\title{
DIPLOMARBEIT
}

\section{Protein-Protein Interactions in TRPC Channel Complexes}

Zur Erlangung des akademischen Grades

Magistra der Pharmazie

An der Naturwissenschaftlichen Fakultät der

Karl-Franzens-Universität Graz

Vorgelegt von:

Michaela Schernthaner

Graz, 2009 
In Dankbarkeit meinen Eltern gewidmet. 
Der experimentelle Teil der vorliegenden Arbeit wurde im Zeitraum von Oktober 2008 bis Juni 2009 am Institut für Pharmakologie und Toxikologie der Universität Graz durchgeführt.

Ich danke Herrn A. o. Univ.-Prof. Dr. Klaus Groschner für die Themenstellung und die freundliche Unterstützung bei der Durchführung der Diplomarbeit.

Besonders bedanken möchte ich mich bei Herrn Mag. Hannes Schleifer, der mir stets mit Rat und Tat zur Seite stand.

Außerdem möchte ich mich bei Herrn Mag. Zora Saad, Frau Mag. Sarah König, Frau Mag. Verena Wenzel und Herrn Dr. Matteo Beretta für die vielen anregenden Diskussionen bedanken.

Weiters danke ich Frau Dr. Annarita Graziani, Herrn Dr. Michael Poteser, Frau Renate Schmidt und allen anderen Mitarbeitern des Instituts.

Special thanks to my younger sister Birgit for her great support during the last weeks.

Diese Arbeit wurde vom Wissenschaftsfond FWF unterstützt.

\section{FUF Der Wissenschaftsfonds.}




\section{$\underline{\text { Table of contents }}$}

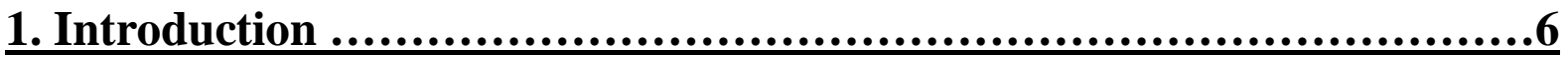

1.1 TRP family of ion channels.........................................6

1.2 TRPC channels.....................................................

1.3 Store - Operated Calcium Entry $\ldots \ldots \ldots \ldots \ldots \ldots \ldots \ldots \ldots \ldots \ldots \ldots \ldots \ldots \ldots$

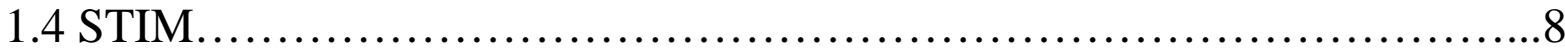

1.5 Orai............................................................ 9

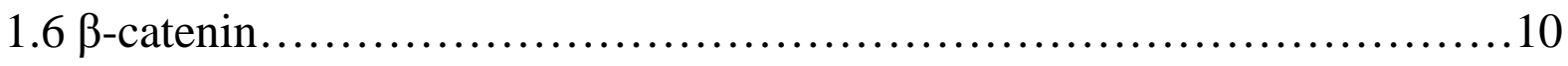

1.7 Protein-Protein Interactions of TRPC channels.........................11

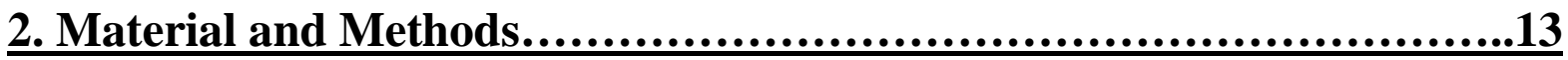

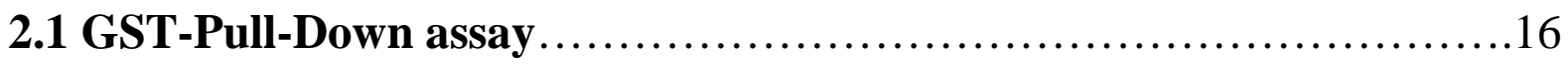

2.1.1 Production of competent cells..................................... 16

2.1.2 Transformation of bacterial cells.....................................16

2.1.3 Protein expression.............................................. 17

2.1.3.1 In Escherichia coli

2.1.3.2 Control of protein expression

2.1.3.3 In vitro transcription and translation

2.1.4 Pull Down....................................................18

2.2 Immunoprecipitation and Western blot...........................19

2.2.1 Transfection methods...........................................19

2.2.1.1 Electroporation of RBL cells

2.2.1.2 Lipofection of HEK 293 cells

2.2.2 Whole cell lysates. 
2.2.4 Western blot...................................................20

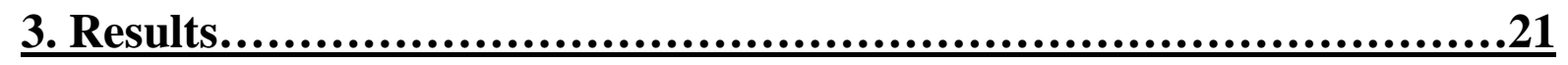

3.1 C-terminal fragments of TRPC3 are sufficient in binding Orai1 full length in

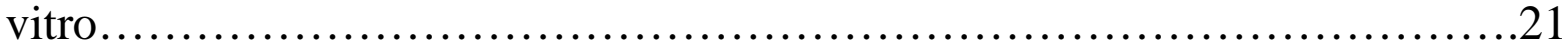

3.2 STIM1-C-terminus does not interact with Orai1 full length in vitro........23

3.3 TRPC3 does not precipitate with STIM1 or Orai1 in RBL wild type cells..25

3.4 TRPC3 precipitates with STIM1 in RBL cells when overexpressed........25

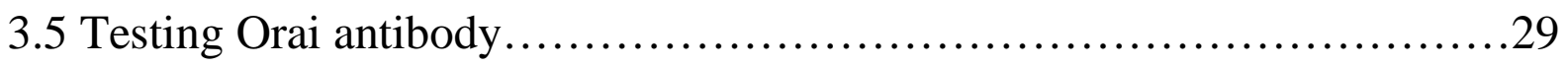

3.6 B-catenin precipitates with TRPC4...............................29

3.7 Fluorescence images of positive transfected HEK 293 cells...............31

3.8 Fluorescence images of positive transfected RBL cells...................32

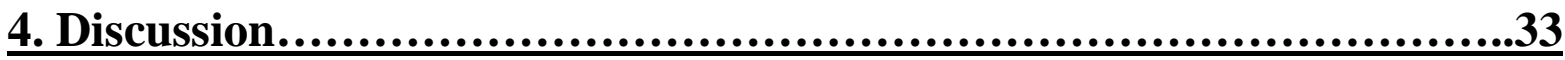

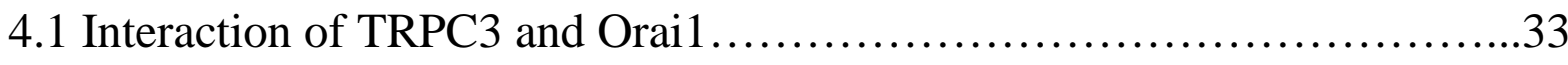

4.2 Interaction of Orai1 and STIM1 .....................................34

4.3 Interaction of TRPC3 and STIM1 ................................. 35

4.4 Interaction of TRPC4 and $\beta$-catenin..................................

5. Abstract $\ldots \ldots \ldots \ldots \ldots \ldots \ldots \ldots \ldots \ldots \ldots \ldots \ldots \ldots \ldots \ldots \ldots \ldots \ldots \ldots \ldots \ldots \ldots \ldots \ldots \ldots \ldots \ldots \ldots \ldots \ldots \ldots \ldots \ldots .37$

6. References............................................................39

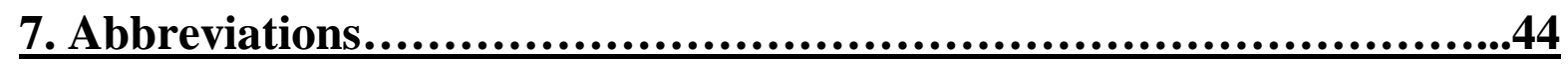




\section{$\underline{1 . \text { Introduction }}$}

\subsection{TRP family of ion channels}

The founding member of this family of ion channels was first cloned in 1989 from Drosophila photoreceptors (Montell and Rubin 1989). Light perception is coupled to activation of PLC mediated by G-protein coupled receptors followed by $\mathrm{Ca}^{2+}$-entry (Hardie and Raghu 2001). If there is a mutation in the TRP (transient receptor potential) gene $\mathrm{Ca}^{2+}$-entry is 10 -fold reduced and the fruit flies show a blind phenotype (Hardie and Minke 1992).

The mammalian TRP channels can be divided into seven families.

TRPC (“Canonical”, TRPC1-TRPC7)

TRPM ("Melastatin”, TRPM1-TRPM8)

TRPV ("Vanniloid", TRPV1-TRPV6)

TRPML ("Mucolipin", 3 members)

TRPP ("Polycystin", 3 members)

TRPA (“Ankyrin”, TRPA1)

TRPN (no mechanoreceptor potential $\mathrm{C}$, not expressed in humans)

The name of each subfamily is based on the original name of the initially described member.
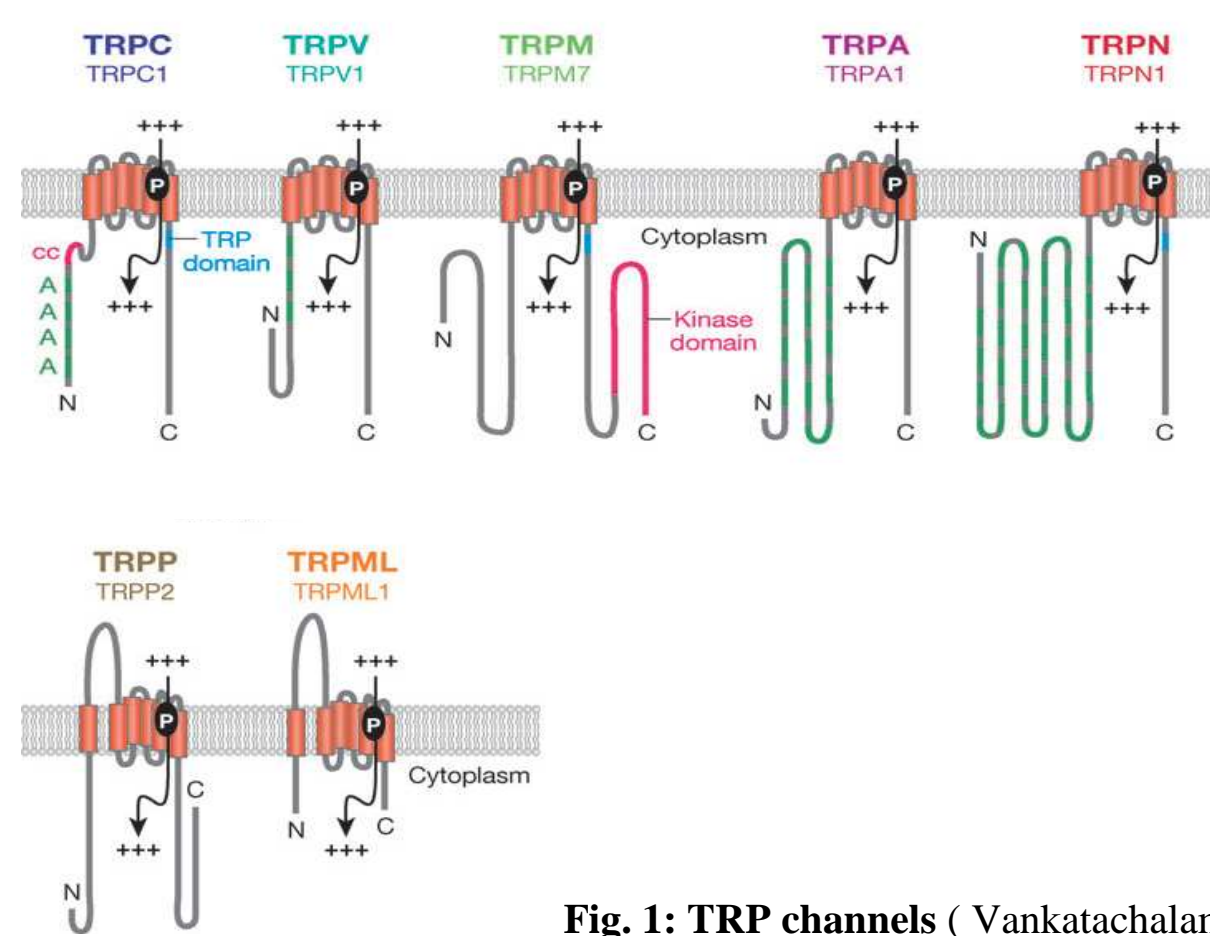

Fig. 1: TRP channels ( Vankatachalam and Montell, 2007) 
All TRP channels share significant sequence homology as well as membrane topology features such as six transmembrane segments and a pore-forming loop between transmembrane segments 5 and 6 . The $\mathrm{N}$ - and C-terminal tails are located in the cytoplasm. There is a highly conserved C-terminal region after the $6^{\text {th }}$ transmembrane domain in TRPCs, TRPNs and TRPMs. It consists of 23-25 amino acids building the so called TRP-Box 1 and TRP-Box 2 (a proline-rich sequence).

They form cation selective channels, but the permeability for mono- and divalent cations varies between the different isoforms.

Many TRP channels are able to form heteromultimers, above all the TRPC channels, resulting in modulation of function, localisation and biophysical properties (Venkatachalam and Montell 2007).

\section{$\underline{1.2}$ TRPC channels}

TRPC1 and TRPC3 were the first mammalian TRPs to be cloned and expressed (Zhu, et al. 1995). The TRPCs can be divided into four subfamilies, according to their sequence homology and functional similarities: TRPC1, TRPC2, TRPC3/6/7, TRPC4/5 (Venkatachalam and Montell 2007). Human TRPC2 encodes only a pseudogene (Wes, et al. 1995).

TRPCs are widely expressed functionally in different tissues and involved in many physiological and pathophysiological processes (Abramowitz and Birnbaumer 2009).

All mammalian TRPCs can be activated by stimulating G-protein coupled receptors, including muscarinic type 1, histaminergic type 1 and purinergic receptors, or tyrosine kinase receptors. Stimulated G-protein coupled receptors activate PLC $\beta$ and tyrosine kinase receptors PLC $\gamma$. After activation PLC hydrolyses $\mathrm{PIP}_{2}$ into two messengers, DAG and InsP $\mathrm{P}_{3}$. $\mathrm{InsP}_{3}$ binds to the $\mathrm{InsP}_{3}$ receptor and causes intracellular $\mathrm{Ca}^{2+}$ release from the endoplasmic reticulum (Clapham 2003).

Other activation mechanisms suggested for TRPC channels are, for example, conformational coupling between $\mathrm{InsP}_{3}$ receptor and TRPC or activation through Diacylglycerol or Lysophosphatidylcholine (Birnbaumer 2009). 


\subsection{Store-operated calcium entry (SOCE)}

Changes in intracellular calcium regulate many important physiological functions in cells. These can be short-term responses like regulation of exocytosis, regulation of enzymatic activity, calcium oscillations and muscle contraction. There are also long-term responses like regulating gene transcription, the cell cycle and apoptosis. Pathophysiological processes, like severe combined immunodeficiency, acute pancreatitis or Alzheimer's disease, occur if the regulation of these essential functions is impaired (Parekh and Putney 2005).

The electrophysiological correlate to store-operated calcium entry is the so called $\mathrm{Ca}^{2+}$ release-activated $\mathrm{Ca}^{2+}$ (CRAC) current or Icrac, which was first identified in mast cells (Hoth and Penner 1992) and in Jurkat T-cells (Zweifach and Lewis 1993).

The Orail protein was identified to mediate the CRAC current, which is highly selective for $\mathrm{Ca}^{2+}$ and inwardly rectifying (Feske, et al. 2006, Vig, et al. 2006, Zhang, et al. 2006). As a calcium sensor for the filling state of the endoplasmic reticulum, STIM1, the stromal interaction molecule, could be identified. It is able to activate the CRAC current after storedepletion (Roos, et al. 2005, Spassova, et al. 2006).

\section{$\underline{1.4 \text { STIM }}$}

STIM1 is a single transmembrane protein in the ER of resting cells with its N-terminus located in the ER lumen and the C-terminus in the cytosol. The $\mathrm{N}$-terminus contains a single EF-hand domain acting as $\mathrm{Ca}^{2+}$ binding motif and as luminal $\mathrm{Ca}^{2+}$ sensor (Liou, et al. 2005), and a SAM domain (sterile-alpha motif) with two N-linked glycosylation sites. After the transmembrane domain there are two coiled-coil regions overlapping with an ERM-like domain (ezrin-radixin-moesin) in the $\mathrm{C}$-terminus followed by a serin-prolin- and a lysine-rich domain (Roos, et al. 2005, Liou, et al. 2005).

STIM2, which is only expressed in mammals (Liou, et al. 2005), shows 61\% structure homology to STIM1, but they diverge significantly after the ERM/coiled-coil domain (Zheng, et al. 2008). The two STIM proteins can form heteromers and STIM2 can act as an inhibitor 
of store operated $\mathrm{Ca}^{2+}$ entry when expressed in HEK293, PC12, A7r5 or Jurkat $\mathrm{T}$ cells (Soboloff, et al. 2006).

Following store-depletion, STIM1 aggregates to puncta located near the plasma membrane and stimulates the CRAC current (Luik, et al. 2006). A small fragment of STIM1-C-terminus, named Orai1 activating small fragment could be identified (OASF, aa 233-450/474). It is able to activate Orail channels independently of store depletion (Muik, et al. 2009).

STIM1 gates TRPC channels by electrostatic interaction. A polybasic domain of STIM1 interacts with two negatively charged amino acids, which are conserved in all TRPCs (Zeng, et al. 2008).
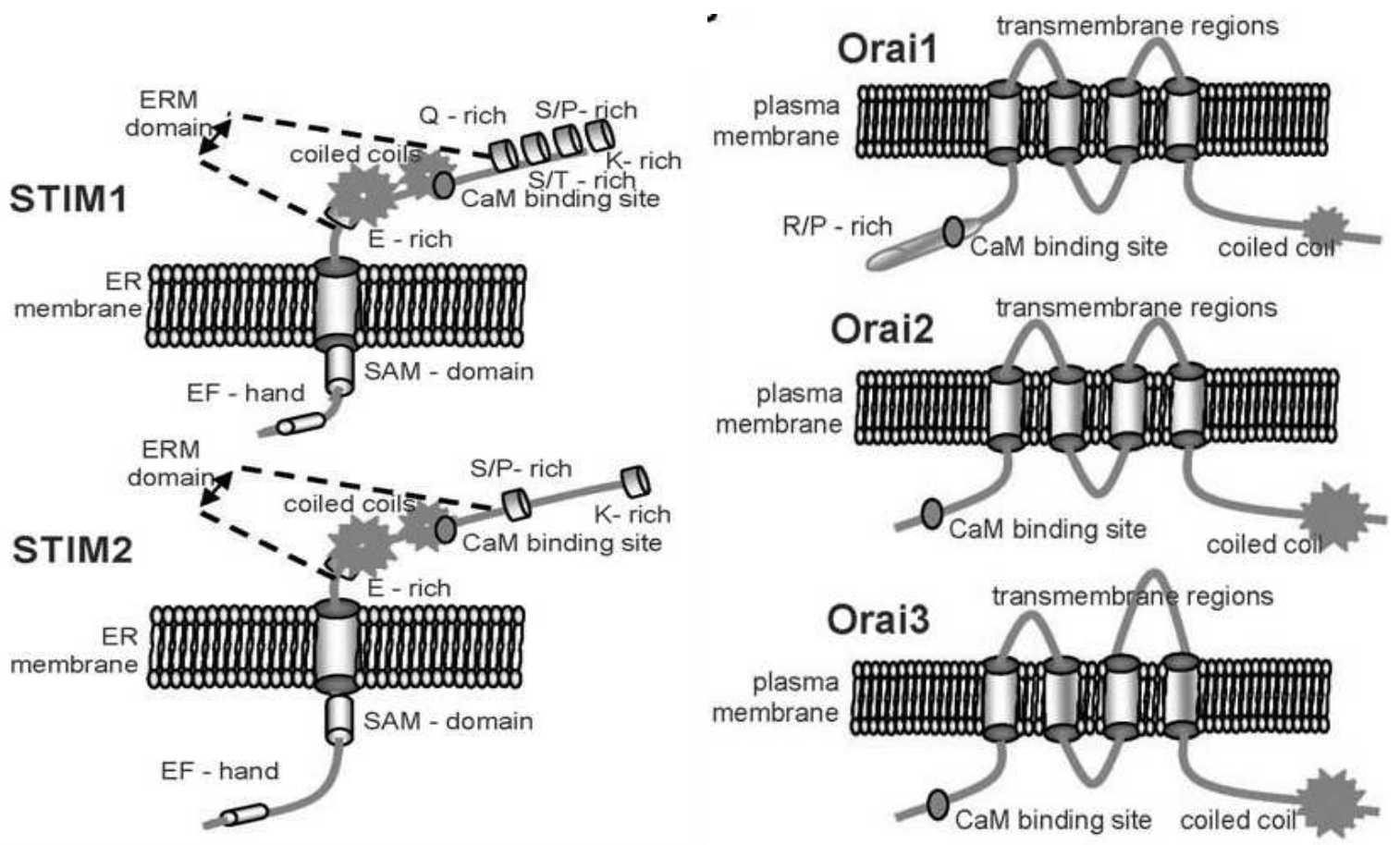

Fig. 2: STIM and Orai proteins (Frischauf et al.2008)

\subsection{Orai}

Up until now, three homologs of the Orai protein expressed in humans could be identified.

The proteins contain four transmembrane domains and both, $\mathrm{N}$ - and C-terminus, are located intracellularly (Vig, et al. 2006). Only Orai1 includes a proline/arginine-rich region in its Nterminus (Cahalan, et al. 2007) but in their C-terminus all three Orai proteins have a putative coiled-coil domain. Orai1 contains an N-glycosylation site on the extracellular loop between 
the third and fourth transmembrane domain, which is absent in Orai2 and Orai3. Glycosylation is not essential for Orai1 function (Gwack, et al. 2007).

All three Orais can be inserted to the plasma membrane. Orail can form homomultimers and also heteromultimers with Orai2 and Orai3 (Gwack, et al. 2007).

Orai 2 and Orai3 can be activated by store-depletion when coexpressed with Stim1, but their current amplitude is 2-3 fold smaller than the one for Orai1 (Lis, et al. 2007).

The CRAC channel pore is formed by Orai tetramers as a result of STIM-induced dimerisation of Orai dimers (Penna, et al. 2008).

\section{$\underline{1.6 \beta \text {-catenin }}$}

$\beta$-catenin was initially characterised as the product of the segment polarity gene Armadillo in Drosophila and contains a central repeat element, named armadillo repeats. The role of $\beta$ catenin in adherens junctions is to create the link between cadherins and the actin cytoskeleton through its interaction with $\alpha$-catenin. It also has an essential role in Wntsignaling were it activates the transcription of target genes which are responsible for cell differentiation and proliferation (Brembeck, et al. 2006).

Most interactions of $\beta$-catenin with other proteins, like the cadherins and T-cell factor (TCF) family members, are mediated by the armadillo repeat domains (Bienz 2005). Moreover, other protein may associate with $\beta$-catenin via PDZ domain interactions. NHERF proteins contain two PDZ domains, so they are able to associate with two different molecules. Theisen et al. identified NHERF-2 as a binding partner of $\beta$-catenin. Their association requires the Cterminal PDZ-binding motive of $\beta$-catenin and the second PDZ domain of NHERF-2. The first PDZ domain of NHERF-2 could bind to other partners, while the second PDZ domain binds to $\beta$-catenin (Theisen, et al. 2007).

Tang et al. showed by coimmunoprecipitation experiments that TRPC4 and TRPC5, as well as PLC- $\beta$ 1/2, are binding partners of the first PDZ domain of NHERF (Tang, et al. 2000). 


\subsection{Protein-Protein Interactions of TRPC channels}

The TRPCs were postulated as pore forming molecules, responsible for receptor and store depletion activated calcium entry (Birnbaumer, et al. 1996). It was shown that TRPC expression enhanced store-depletion activated calcium entry and that the genetic ablation or injection of specific anti-TRPC antibodies reduced store-operated calcium entry (Zagranichnaya, et al. 2005).

In 2006 three laboratories reported that the Orai proteins could be the molecular candidate for store-operated calcium entry, which is responsible for Icrac, the store-depletion activated calcium current, without involvement of TRPC channels (Feske 2007, Hogan and Rao 2007, Vig and Kinet 2007).

In the end of 2006 Birnbaumer and collaborators reported that TRPC channels interact with Orai proteins. They showed with in-vitro pull down experiments that Orail can form, with preferences for the C-termini, complexes with TRPC3 and TRPC6. Thus, they predicted a model of store-operated calcium entry and/or Icrac channels built up of TRPC channels as pore forming $\alpha$-subunits and Orai proteins as regulatory $\beta$-subunits. The latter mediates a store-depletion signal from STIM to TRPC. The conclusion was that TRPC channels can act as receptor-operated channels through activation by $\mathrm{PLC}$ and $\mathrm{InsP}_{3}$ signalling or they can be STIM1-Orai1-controlled store-operated channels (Liao, et al. 2007).

In a later study they present a theory of STIM-regulated heteromeric TRPC/Orai channels which mediate receptor-operated calcium entry when activated outside lipid rafts and storeoperated calcium entry when activated inside lipid rafts (Liao, et al. 2009).

In a study of Vaca and collaborators (Alicia, et al. 2008) it was found out that TRPC1 concentrates in lipid rafts only when STIM1 is coexpressed. Otherwise TRPC1 is located in other fractions.

Huang et al. reported that STIM1 binds TRPC1, TRPC4 and TRPC5, but not TRPC3, TRPC6 and TRPC7. Furthermore it regulates all TRPC channels, except TRPC7, directly or indirectly (Huang, et al. 2006). 
TRPC1, TRPC4 and TRPC5 are regulated directly, but the regulation of TRPC3 and TRPC6 is mediated by a STIM1-dependent heteromultimerisation of TRPC3 with TRPC1 and TRPC6 with TRPC4. STIM1 is not essential for channel function but required for TRPC channels to be activated by agonist stimulation. They could show that TRPC3 is a STIM1-regulated channel when expressed at low levels and that TRPC3 coimmunoprecipitates with STIM1 when coexpressed with TRPC1. STIM1 is required for the interaction of TRPC3 and TRPC1. Knock down of STIM1 significantly reduces the coimmunoprecipitation of TRPC3 and TRPC1. When TRPC3 is overexpressed, there are large fractions of not complexed TRPC3 which can be activated by agonist in a STIM1-independent manner.

Coexpression of TRPC4 and TRPC6 led to coimmunoprecipitation of TRPC6 with STIM1 and TRPC4 coimmunoprecipitates with TRPC6 in the presence of STIM1 also (Yuan, et al. 2007).

Evidence for TRPC4 being a SOCE-forming channel was reported by Freichel et al. They described a store-operated $\mathrm{Ca}^{2+}$ current in the vascular endothelium and showed that this current is lacking in endothelial cells of TRPC4 deficient mice (Freichel, et al. 2001). Tiruppathi showed that the deletion of TRPC4 in mice causes an impairment of store-operated $\mathrm{Ca}^{2+}$ entry that interferes with an increase in lung microvascular permeability (Tiruppathi, et al. 2002).

As mentioned above, TRPC4 and TRPC5 could be identified as binding partners of the first PDZ domain of NHERF (Tang, et al. 2000).

EBP50, the human ortholog of NHERF, binds to TRPC4 via the last three amino acids of TRPC4-C-terminus (TRL), which comprise a PDZ-interacting domain. The interaction with EBP50 seems to control the surface expression of TRPC4, because deletion of the PDZinteracting domain decreases the plasma membrane expression of TRPC 4 by 2.4 fold and a mutant lacking the TRL motif accumulates into cell outgrowths (Mery, et al. 2002). 


\section{Material and Methods}

Table 1: LB-medium pH 7.4

\begin{tabular}{|l|c|}
\hline \multicolumn{1}{|c|}{ Composition } & Percent \\
\hline Trypton (Oxoid) & $1 \%(\mathrm{~m} / \mathrm{v})$ \\
\hline Yeast-extract (Oxoid) & $0.5 \%(\mathrm{~m} / \mathrm{v})$ \\
\hline $\mathrm{NaCl}$ & $1 \%(\mathrm{~m} / \mathrm{v})$ \\
\hline
\end{tabular}

Table 3: Lämmli buffer

\begin{tabular}{|l|c|}
\hline \multicolumn{1}{|c|}{ Composition } & Percent /Molarity \\
\hline TRIZMA Base ${ }^{\circledR}$ & $50 \mathrm{mM}$ \\
\hline Glycerol & $10 \%$ \\
\hline 2-Mercaptoethanol & $5 \%$ \\
\hline SDS & $2 \%$ \\
\hline Bromphenoleblue & $0.1 \%$ \\
\hline
\end{tabular}

Table 5: Coomassie blue staining sol.

\begin{tabular}{|l|c|}
\hline \multicolumn{1}{|c|}{ Composition } & Percent \\
\hline Methanol & $50 \%(\mathrm{~V} / \mathrm{V})$ \\
\hline Acetic acid & $7.5 \%(\mathrm{~V} / \mathrm{V})$ \\
\hline Coomassie Brilliant Blue & $0.25 \%(\mathrm{~m} / \mathrm{V})$ \\
\hline Aqua dest. & $42.25 \%(\mathrm{~V} / \mathrm{V})$ \\
\hline
\end{tabular}

Table 2: 10x PBS buffer pH 6.9

\begin{tabular}{|l|c|}
\hline \multicolumn{1}{|c|}{ Composition } & Amount \\
\hline $\mathrm{NaCl}$ & $80 \mathrm{~g}$ \\
\hline $\mathrm{KCl}$ & $2 \mathrm{~g}$ \\
\hline $\mathrm{NaHPO}_{4}$ & $144 \mathrm{~g}$ \\
\hline $\mathrm{KH}_{2} \mathrm{PO}_{4}$ & $2 \mathrm{~g}$ \\
\hline Aqua dest. & 11 \\
\hline
\end{tabular}

Table 4: Running buffer

\begin{tabular}{|l|c|}
\hline \multicolumn{1}{|c|}{ Composition } & Amount \\
\hline TRIZMA Base ${ }^{\circledR}$ & $30.2 \mathrm{~g}$ \\
\hline Glycine & $188 \mathrm{~g}$ \\
\hline SDS $(10 \%)$ & $100 \mathrm{ml}$ \\
\hline Milli-Q-Water & 21 \\
\hline
\end{tabular}

Table 6: Destaining solution

\begin{tabular}{|l|c|}
\hline \multicolumn{1}{|c|}{ Composition } & Percent \\
\hline Methanol & $10 \%(\mathrm{~V} / \mathrm{V})$ \\
\hline Acetic acid & $10 \%(\mathrm{~V} / \mathrm{V})$ \\
\hline Aqua dest. & $80 \%(\mathrm{~V} / \mathrm{V})$ \\
\hline
\end{tabular}


Table 7: Fixing solution I

\begin{tabular}{|l|c|}
\hline \multicolumn{1}{|c|}{ Composition } & Percent \\
\hline Methanol & $50 \%(\mathrm{~V} / \mathrm{V})$ \\
\hline Acetic acid & $10 \%(\mathrm{~V} / \mathrm{V})$ \\
\hline Aqua dest. & $40 \%(\mathrm{~V} / \mathrm{V})$ \\
\hline
\end{tabular}

Table 9: Trypsin/PBS

\begin{tabular}{|l|c|}
\hline \multicolumn{1}{|c|}{ Composition } & Amount \\
\hline Trypsin & $250 \mathrm{mg}$ \\
& \\
\hline EDTA & $5 \mathrm{ml}$ \\
\hline PBS & $500 \mathrm{ml}$ \\
\hline
\end{tabular}

Table 11: Bradford Reagent

\begin{tabular}{|l|c|}
\hline \multicolumn{1}{|c|}{ Composition } & Amount \\
\hline Coomassie Brilliant Blue & $40 \mathrm{~g}$ \\
\hline Ethanol (95\%) & $10 \mathrm{ml}$ \\
\hline $\mathrm{H}_{3} \mathrm{PO}_{4}$ & $20 \mathrm{ml}$ \\
\hline Aqua dest. & $200 \mathrm{ml}$ \\
\hline
\end{tabular}

Table 8: Fixing solution II

\begin{tabular}{|l|c|}
\hline \multicolumn{1}{|c|}{ Composition } & Percent \\
\hline Methanol & $7 \%(\mathrm{~V} / \mathrm{V})$ \\
\hline Acetic acid & $7 \%(\mathrm{~V} / \mathrm{V})$ \\
\hline Glycerol & $1 \%(\mathrm{~V} / \mathrm{V})$ \\
\hline Aqua dest. & $85 \%(\mathrm{~V} / \mathrm{V})$ \\
\hline
\end{tabular}

Table 10: Medium

\begin{tabular}{|l|c|}
\hline \multicolumn{1}{|c|}{ Composition } & Percent \\
\hline $\begin{array}{l}\text { DMEM D1152 (PAA } \\
\text { Laboratories) }\end{array}$ & $90 \%$ \\
\hline FBS (PAA Laboratories) & $10 \%$ \\
\hline
\end{tabular}

Table 12: 10x TBS buffer pH 7,6

\begin{tabular}{|l|c|}
\hline \multicolumn{1}{|c|}{ Composition } & Amount \\
\hline $\mathrm{NaCl}$ & $80 \mathrm{~g}$ \\
\hline TRIZMABase $\AA$ & $24.4 \mathrm{~g}$ \\
\hline Aqua dest. & 11 \\
\hline
\end{tabular}


Table 13: Dilutions of antibodies

\begin{tabular}{|c|c|c|c|}
\hline \multicolumn{2}{|l|}{ prim. antibody } & \multicolumn{2}{|l|}{ sec. antibody } \\
\hline antibody & dilution & antibody & dilution \\
\hline $\begin{array}{l}\text { Rabbit polyclonal } \\
\text { anti-TRPC3 }\end{array}$ & $\begin{array}{l}1: 1000 \text { in TBST }+ \\
1 \% \text { milk }\end{array}$ & $\begin{array}{l}\text { Goat anti-rabbit IgG- } \\
\text { HRP (Santa Cruz) }\end{array}$ & $\begin{array}{l}1: 5000 \text { in TBST }+ \\
1 \% \text { milk }\end{array}$ \\
\hline $\begin{array}{l}\text { Rabbit polyclonal } \\
\text { anti-STIM } 1\end{array}$ & $\begin{array}{l}1: 1000 \text { in PBST }+ \\
1 \% \text { milk }\end{array}$ & $\begin{array}{l}\text { Goat anti-rabbit IgG- } \\
\text { HRP (Santa Cruz) }\end{array}$ & $\begin{array}{l}1: 5000 \text { in TBST }+ \\
1 \% \text { milk }\end{array}$ \\
\hline $\begin{array}{l}\text { Rabbit polyclonal } \\
\text { anti-Orai } 1 \text { (ProSci) }\end{array}$ & $\begin{array}{l}1: 1000 \text { in PBST }+ \\
1 \% \text { milk }\end{array}$ & $\begin{array}{l}\text { Goat anti-rabbit IgG- } \\
\text { HRP (Santa Cruz) }\end{array}$ & $\begin{array}{l}1: 5000 \text { in TBST }+ \\
1 \% \text { milk }\end{array}$ \\
\hline $\begin{array}{l}\text { Rabbit polyklonal } \\
\text { anti-Orai } 3 \text { (PrpSci) }\end{array}$ & $\begin{array}{l}1: 1000 \text { in PBST }+ \\
1 \% \text { milk }\end{array}$ & $\begin{array}{l}\text { Goat anti-rabbit IgG- } \\
\text { HRP (Santa Cruz) }\end{array}$ & $\begin{array}{l}1: 5000 \text { in TBST }+ \\
1 \% \text { milk }\end{array}$ \\
\hline $\begin{array}{l}\text { Mouse monoclonal } \\
\text { anti-GFP } \\
\text { (ROCHE Diagnostics) }\end{array}$ & $\begin{array}{l}1: 1000 \text { in PBST }+ \\
1 \% \text { milk }\end{array}$ & $\begin{array}{l}\text { Goat anti-mouse IgG } \\
\text { HRP } \\
\text { (BD Pharmingen }^{\mathrm{TM}} \text { ) }\end{array}$ & $\begin{array}{l}1: 5000 \text { in TBST }+ \\
1 \% \text { milk }\end{array}$ \\
\hline $\begin{array}{l}\text { Rabbit polyclonal } \\
\text { anti-TRPC4 } \\
\text { (Alomone) }\end{array}$ & $\begin{array}{l}1: 200 \text { in PBST }+ \\
5 \% \text { milk }\end{array}$ & $\begin{array}{l}\text { Goat anti-rabbit IgG- } \\
\text { HRP (Santa Cruz) }\end{array}$ & $\begin{array}{l}1: 3000 \text { in PBST }+ \\
1 \% \text { milk }\end{array}$ \\
\hline $\begin{array}{l}\text { Mouse monoclonal } \\
\text { anti-\$-catenin } \\
\text { ( BD Healthcare) }\end{array}$ & $\begin{array}{l}1: 1000 \text { in PBST }+ \\
1 \% \text { milk }\end{array}$ & $\begin{array}{l}\text { Goat anti-mouse IgG } \\
\text { HRP } \\
\text { (BD Pharmingen }^{\mathrm{TM}} \text { ) }\end{array}$ & $\begin{array}{l}1: 5000 \text { in PBST }+ \\
1 \% \text { milk }\end{array}$ \\
\hline
\end{tabular}




\subsection{GST-Pull Down Assay}

To get a GST-fusion protein a gene sequence is cloned into a plasmid where it gets fused to the C-terminus of Glutathione-S-Transferase when expressed. The obtained protein can be immobilized by binding to Glutathione-Sepharose-beads. Bound on the beads, it acts as bait for a pray-protein in solution.

If a bait-pray-complex occurs, it can be purified, separated by SDS PAGE and detected by autoradiography.

\subsubsection{Production of competent cells}

$500 \mathrm{ml}$ of LB-medium (Table 2) were inoculated with a BL-21-D3 over night culture in a ratio of $1: 100$. After shaking the culture at $37^{\circ} \mathrm{C}$ until an optical density of $0.5-0.7$, measured at $600 \mathrm{~nm}$, was achieved, it was put on ice for 15-30 min. Afterwards it was centrifuged for 15 min. at $4000 \mathrm{~g}$ in a precooled rotor at $4^{\circ} \mathrm{C}$. The supernatant was discarded and the cells were resuspended in ice cold sterile $10 \%(\mathrm{~V} / \mathrm{V})$ glycerine solution. The cells were centrifuged again for 3 times. The first time, the resuspension volume was reduced to $250 \mathrm{ml}$, then to 10 $\mathrm{ml}$ and finally to $2 \mathrm{ml}$.

$100 \mu \mathrm{l}$ aliquots were prepared, flash-frozen in liquid nitrogen and stored at $-70^{\circ} \mathrm{C}$.

\subsubsection{Transformation of bacterial cells by electroporation}

The cuvettes for electroporation have to be precooled on ice before use. For one reaction $45 \mu \mathrm{l}$ of bacterial cells and 2-5 $\mu \mathrm{l}$ ( about $10 \mathrm{ng}$ of DNA) were mixed in a cuvette and shocked with $1.5 \mathrm{kV}$ for $5 \mathrm{~ms}$. in the electroporator ( BTW TransPoratorPlus).

Immediately after the shock, the cells were pipetted into $500 \mu 1$ of LB-medium, preheated to $42^{\circ} \mathrm{C}$, and shaken overhead for $1 \mathrm{~h}$ at $37^{\circ} \mathrm{C} .250 \mu \mathrm{l}$ of the cell suspension were plated on ampicillin-agar-plates and incubated over night at $37^{\circ} \mathrm{C}$.

On the following day, $3 \mathrm{ml}$ cultures of LB medium, containing $100 \mu \mathrm{g} / \mathrm{ml}$ ampicillin, were inoculated with single colonies picked off the plates.

The colonies were shaken over day at $37^{\circ} \mathrm{C}$. In the evening, $50 \mathrm{ml}$ cultures were inoculated with $100 \mu \mathrm{l}$ of the $3 \mathrm{ml}$ cultures and shaken over night at $37^{\circ} \mathrm{C}$. 


\subsubsection{Protein expression}

\subsubsection{In Escherichia coli}

$200 \mathrm{ml} \mathrm{LB}$-medium, containing $100 \mu \mathrm{g} / \mathrm{ml}$ ampicillin, were inoculated with an over night culture to get an optical density of 0.5 . It was shaken at $37^{\circ} \mathrm{C}$ until an optical density of 1 was achieved. Two different plasmids were used for the synthesis of the fusion proteins. The pGEX-4T-1 plasmid, used for the production of TRPC3-C-terminal fragments, was induced by $0.1 \mathrm{mM}$ IPTG (isopropyl-ß-D-thiogalactopyranoside ).

The pBADM-30 plasmid, used for the production of STIM1-C-terminal fragment, was induced by $0.2 \%$ Arabinose.

The culture was shaken for $4 \mathrm{~h}$ at room temperature. Afterwards the culture was centrifuged with $3000 \mathrm{rpm}$ at $4^{\circ} \mathrm{C}$ for $10 \mathrm{~min}$ and the supernatant was discarded. The pellet was resuspended in $20 \mathrm{ml}$ ice cold PBS (Table 3) and after adding protease inhibitors (Complete Protease Inhibitor Cocktail Tablets, ROCHE) it was stored at $-20^{\circ} \mathrm{C}$.

After thawing, $1 \%$ Triton-X-100 was added. The cells were lysed by sonification for 4 times for $20 \mathrm{sec}$. and put on ice in between. The obtained lysate was centrifuged with $10000 \mathrm{rpm}$ at $4^{\circ} \mathrm{C}$ for $20 \mathrm{~min}$. The supernatant was transferred to a new $50 \mathrm{ml}$ vial. The cells were resuspended in $10 \mathrm{ml}$ ice cold PBS and sonicated again for 4 times for $15 \mathrm{sec}$. The lysate was centrifuged with $10000 \mathrm{rpm}$ at $4^{\circ} \mathrm{C}$ for $10 \mathrm{~min}$. The supernatant was united with the previous one. $500 \mu \mathrm{l}$ of Glutathione-Sepharose-beads were prepared by washing 3 times with PBS. According to the manufacturer's manual the beads can be centrifuged only with a maximum of $500 \mathrm{~g}$. The washed beads were added to the supernatant and shaken overhead for $30 \mathrm{~min}$. at

$4^{\circ} \mathrm{C}$. After centrifugation the beads were washed again 3 times with PBS. The beads were resuspended in a volume of PBS, including protease inhibitor, so that a $50 \%$ slurry was obtained which was stored at $4^{\circ} \mathrm{C}$.

\subsubsection{Control of the protein expression by SDS-PAGE}

A $50 \mu \mathrm{l}$ aliquot of the slurry was mixed with 2x Lämmli buffer (Table 4) to release the bound protein. The mix was boiled up for $3 \mathrm{~min}$. at $95^{\circ} \mathrm{C}$ and centrifuged at high speed for $2 \mathrm{~min}$. The supernatant could be frozen and stored at $-20^{\circ} \mathrm{C}$ or directly loaded onto a polyacrylamid gel. With a voltage of $150 \mathrm{~V}$ the separation took about one hour.

The protein bands became visible by staining with Coomassie brilliant blue (Table 6,7). Band intensities were determined by densitometric analysis (HEROLAB, E.A.S.Y. win 32 system). 


\subsubsection{In vitro transcription and translation}

The pray-protein, Orail full length, was produced with the TNT® Coupled Reticulocyte Lysate System (Promega Corporation, USA). The protein was radiolabeled by adding ${ }^{35} \mathrm{~S}$ methionine and could be detected by autoradiography.

Table 14: pipetting schema

\begin{tabular}{|l|c|}
\hline TNT® Rabbit Reticulocyte Lysate & $12.5 \mu \mathrm{l}$ \\
\hline TNT® Reaction Buffer & $1.0 \mu \mathrm{l}$ \\
\hline TNT® RNA Polymerase & $1.0 \mu \mathrm{l}$ \\
\hline Amino Acid Mix minus Methionine, $1 \mathrm{mM}$ & $0.5 \mu \mathrm{l}$ \\
\hline$\left.{ }^{35} \mathrm{~S}\right]$ Methionine $(10 \mathrm{mCi} / \mathrm{ml})$ & $2.0 \mu \mathrm{l}$ \\
\hline RNasin $®$ Ribonucleaseinhibitor (Promega) & $1.0 \mu \mathrm{l}$ \\
\hline DNA template $(1 \mu \mathrm{g} / \mu \mathrm{l})$ & $1.0 \mu \mathrm{l}$ \\
\hline Nuclease free water $($ Ambion) & $6.0 \mu \mathrm{l}$ \\
\hline & $\Sigma 25.0 \mu \mathrm{l}$ \\
\hline
\end{tabular}

All steps were carried out on ice. The mix was incubated on a heating block for $90 \mathrm{~min}$. at $30^{\circ} \mathrm{C}$.

\subsubsection{Pull Down}

$6 \mu \mathrm{l}$ of radiolabeled pray-protein were mixed with $100 \mu \mathrm{l}$ bait-protein bound on beads and PBS to a final volume of $500 \mu$ l. To equalize the different concentrations of the bait-protein, the higher expressing ones were diluted with empty, washed beads.

The mix was shaken overhead for $2 \mathrm{~h}$ at $4^{\circ} \mathrm{C}$ and then centrifuged with $500 \mathrm{~g}$. The beads were washed 3 times with PBS, boiled up with $2 x$ Lämmli buffer for $3 \mathrm{~min}$. at $95^{\circ} \mathrm{C}$ and were centrifuged at high speed for $2 \mathrm{~min}$.

To analyse the retention of Orai1, the supernatant was directly loaded onto a polyacrylamid gel. After the separation, the gel was put into fixing solution I (Table 8) for $30 \mathrm{~min}$. and into fixing solution II (Table 9) for $5 \mathrm{~min}$. The gel was dried under vacuum at $70^{\circ} \mathrm{C}$. A Kodak XOmat LS film (Sigma) was put on the gel and exposed for $24-36 \mathrm{~h}$. The film was developed with G150 Developer (AGFA) and fixed with G328 Fixer (AGFA). Finally, the bands were quantified by densitometric analysis.

Statistical differences were considered as statistically significant at a p-level of $\mathrm{p} \square 0.05$. 


\section{$\underline{\text { 2.2 Immunoprecipitation and Western blot }}$}

\subsubsection{Transfection methods}

\subsubsection{Electroporation of RBL-cells}

The medium (Table 10) and the trypsin solution (Table 9) were preheated to $37^{\circ} \mathrm{C}$. The medium of the Petri dish was discarded and the cells were washed twice with PBS. After incubation with trypsin solution for $5 \mathrm{~min}$. at $37^{\circ} \mathrm{C}$, the cells could be washed off the Petri dish and transferred to a new vial containing medium. The cells were pelletet by centrifugation for 5-10 min. with $1000 \mathrm{rpm}$ and the supernatant was discarded. The pellet was resuspended with $400 \mu \mathrm{l}$ OPTI-MEM®I (Invitrogen). A Petri dish with $1 \mathrm{ml}$ medium was prepared. $10 \mu \mathrm{g}$ DNA were transferred into precooled cuvettes with a $4 \mathrm{~mm}$ gap and the resuspended cells were added. The mix was shocked with $0.4 \mathrm{kV}$ in the electroporator $\left(\operatorname{BioRad}^{\mathrm{TM}}\right)$, picked up with $800 \mu \mathrm{l}$ of medium and transferred into the prepared dish. The cells were incubated for $24 \mathrm{~h}$.

\subsubsection{Lipofection of HEK293-cells}

The medium was removed and the cells were washed twice with PBS. $600 \mu$ I OPTI-MEM®I, $4 \mu \mathrm{g}$ DNA and $6 \mu \mathrm{l}$ Transfast (Promega) were mixed in this order and $15 \mathrm{~min}$. later added onto the cells which then were incubated for $2 \mathrm{~h}$. After adding $1 \mathrm{ml}$ medium they were incubated again for $24 \mathrm{~h}$.

\subsubsection{Whole cell lysates}

The cells were scraped off from the dishes in $5 \mathrm{ml}$ of PBS and centrifuged for $5 \mathrm{~min}$. with 900 $\mathrm{rpm}$ at $4^{\circ} \mathrm{C}$. The supernatant was discarded and the pellet was lysed with $500 \mu 1$ Mammalian Cell Lysis Buffer (QUIAGEN), containing $5 \mu$ Protease Inhibitor Solution. The lysate was shaken overhead for $20 \mathrm{~min}$. at $4^{\circ} \mathrm{C}$ and centrifugated with $13000 \mathrm{rpm}$ for $5 \mathrm{~min}$. The supernatant, now a cleared lysate, was transferred to a new $1.5 \mathrm{ml}$ vial. Protein concentrations were determined by the Bradford test (Bradford and Richards 1976).

The cleared lysate could be used for immunoprecipitation or boiled up with 5x Lämmli buffer for western blot analysis. 


\subsubsection{Immunoprecipitation}

Aliquots of the cleared lysate, containing $500 \mu \mathrm{g}$ of protein, were incubated with $50 \mu \mathrm{l}$ of washed protein-A- and protein-G-beads, respectively, and PBS for a final volume of $500 \mu 1$. They were shaken overhead for 40-50 min. at $4^{\circ} \mathrm{C}$ and centrifuged with $3000 \mathrm{rpm}$ for 10 min. at $4^{\circ} \mathrm{C}$. The supernatant, now called precleared lysate, was transferred to new $1.5 \mathrm{ml}$ vials. $3 \mu \mathrm{g}$ of the indicated antibody were added to the aliquots, excluding one for control, and were shaken overnight at $4^{\circ} \mathrm{C}$.

On the following day, $60 \mu \mathrm{l}$ of washed protein-A and protein-G-beads were added, respectively, and shaken overhead for $2 \mathrm{~h}$ at room temperature. The beads were washed afterwards for 4 times with PBS and shaken overhead for $10 \mathrm{~min}$. in between. After the last centrifugation, the supernatant was discarded and the beads were boiled up with 2x Lämmli buffer for $3 \mathrm{~min}$. at $95^{\circ} \mathrm{C}$ and centrifuged with high speed. The supernatant could be stored at $-20^{\circ} \mathrm{C}$ or used directly.

\section{$\underline{\text { 2.2.4 Western blot }}$}

The immunocomplexes and cell lysates were separated by SDS PAGE and transferred to a nitrocellulose membrane, followed by blocking overnight with $5 \%$ non-fat dry milk in PBST $\left(0,1 \%\right.$ Tween ${ }^{\circledR}$ in PBS $)$ and TBST $\left(0,2 \%\right.$ Tween ${ }^{\circledR} 20$ in TBS $)$, respectively. On the next day the membrane was incubated in primary antibody for $1 \mathrm{~h}$ at room temperature and after 4 ten minute washes the secondary antibody was applied for $1 \mathrm{~h}$ and the washing was repeated. Dilutions of the antibodies were used according to Table 13.

After 5 min. incubation in ChemiGlow West Chemieluminescence Substrate Sample Kit (Alpha Innotech), the bands could be detected densitometrically. 


\section{Results}

\subsection{C-terminal fragments of TRPC3 are sufficient in binding Orai1 full length in vitro}

To evaluate the expression of the GST-fused fragments and the vector, proteins were separated by SDS PAGE and stained with Coomassie brilliant blue as shown in Fig. 3 A). The molecular weights of the GST-tagged fragments of TRPC3-C-terminus, aa 670-797 and aa 742-848, add up to $41.4 \mathrm{kDa}$ and $38.6 \mathrm{kDa}$, respectively. Although unspecific bands were observed on the gel, expression of the fusion protein was clearly detectable and found to be high enough for the planned experimental strategy. The bands representing the fusion proteins and GST as a control are marked with arrows.

As positive control for effective in vitro transcription and translation, the input of ${ }^{35} \mathrm{~S}$-labeled Orail is shown in lane 1 on the autoradiogram in Fig. 3 B). Lane 2 and 3 represent the retention of Orai1 on the fragments of TRPC3-C-terminus. For Orai1 and GST without fused fragment, almost no interaction was detectable.

As evident from the diagram in Fig. 3 C), the retention of Orail on fragment aa 670-797 was 2.6 fold higher than for fragment aa 742-848.

The data are presented as the means \pm S.D. The statistical significance was determined by Student's $t$ test for unpaired values $(\mathrm{p}<0.05)$. 
A)

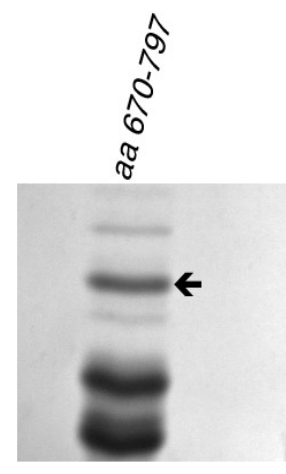

1

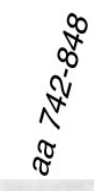

ชิ
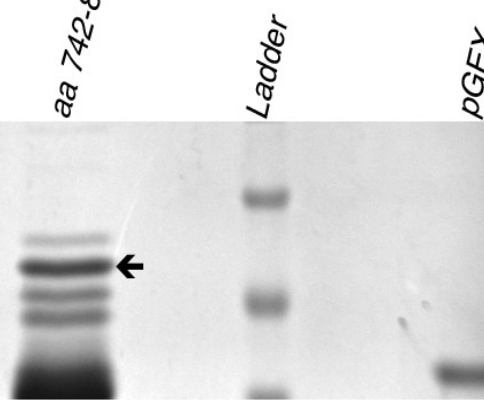

2

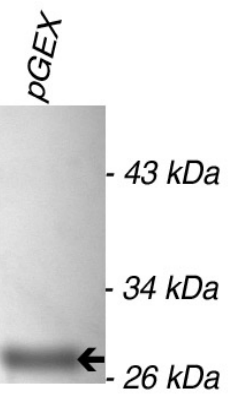

4
B)

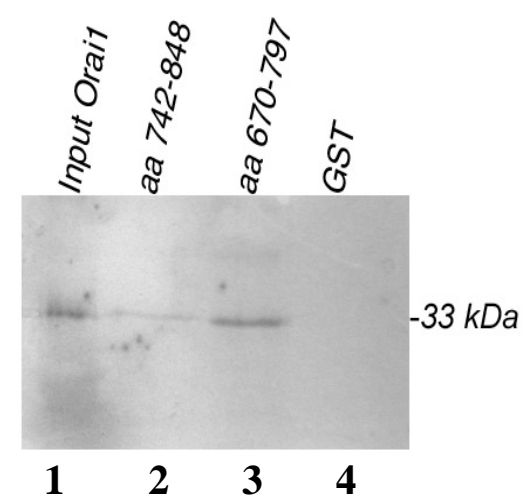

C)

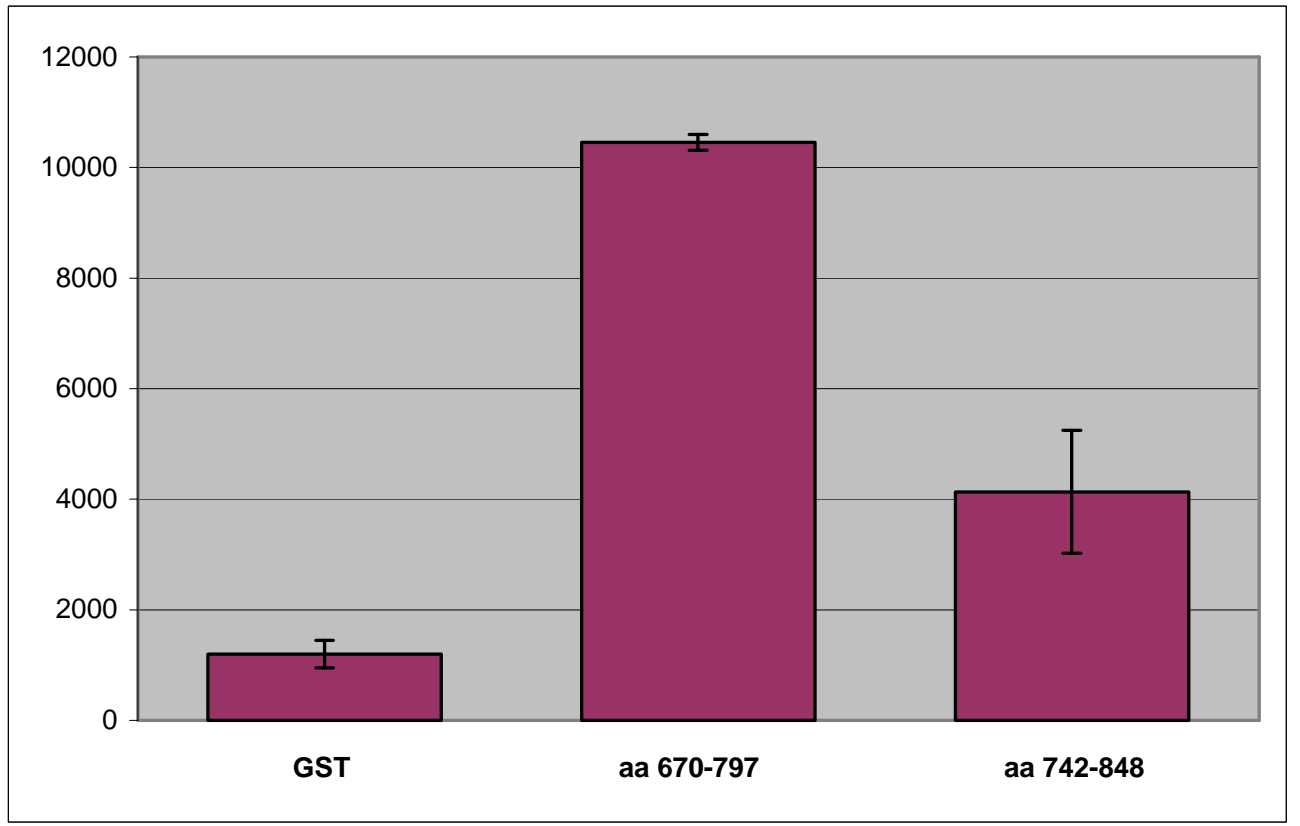

\begin{tabular}{ccc} 
GST & aa 670-797 & aa 742-848 \\
\hline 1026 & 10353 & 3346 \\
1328 & 10556 & 4922 \\
\hline $1202 \pm 248,9$ & $10454,5 \pm 143,5$ & $4134 \pm 1114,4$
\end{tabular}

Figure 3: C-terminal fragments of TRPC3 are sufficient to bind Orai1 full length in vitro

A) Protein expression in E. coli (see 2.1.3); first fragment of TRPC3-C-terminus consists of amino acids $670-797(13.4 \mathrm{kDa})+\mathrm{GST}-\mathrm{Tag}(28 \mathrm{kDa})$ and migrates at $41.4 \mathrm{kDa}$ (arrow, lane 1), second fragment consists of amino acids 742-848 (10.6 kDa) + GSTTag (28 kDa) and migrates at $38.6 \mathrm{kDa}$ (arrow, lane 2); PageRuler ${ }^{\mathrm{TM} P r e s t a i n e d-}$ Protein-Ladder, Fermentas (lane 3); vector control (GST, arrow, lane 4)

B) GST-Pull-Down (as described in method part); Autoradiogramm: Input of in vitrotranslated ${ }^{35} \mathrm{~S}$-labeled Orai1 (lane 1), Retention of Orai1 on the C-terminal fragments of TRPC3 (lane 2,3), retention with GST without fused fragments (lane 4)

C) Diagram and Table of mean values; mean of arbitrary units obtained by densitometrical analysis are shown for GST and the two fragments aa 670-797, aa $742-848$ 


\section{$\underline{\text { 3.2 STIM1-C-terminus does not interact significantly with Orai1 full length in vitro }}$}

To evaluate the expression of GST-fused STIM1 and its vector, proteins were separated by SDS PAGE and stained with Coomassie brilliant blue (Fig. 4 A). GST-tagged STIM1-Cterminus has a molecular weight of $90 \mathrm{kDa}$. Although unspecific bands were observed on the gel, expression of the fusion proteins was clearly detectable and found to be high enough. The bands representing the fusion protein and GST as a control are marked with arrows.

Lane 1 of the autoradiogram in Fig. 4 B) shows the retention of Orai1 on STIM1-C-terminus. Lane 2 shows that there was also retention of Orail on GST without fused fragments. As positive control for effective in vitro transcription and translation, the input of ${ }^{35} \mathrm{~S}$-labeled Orai1 is shown in lane 3.

As evident from the diagram in Fig. 4 C) the interaction of STIM1-C-terminus and Orai1 was obviously not statistically significant as compared to GST controls in these in vitro experiments.

The data are presented as means \pm S.D. The statistical significance was determined by Student's t test for unpaired values ( $\mathrm{p} \square 0.05$.). 
A)

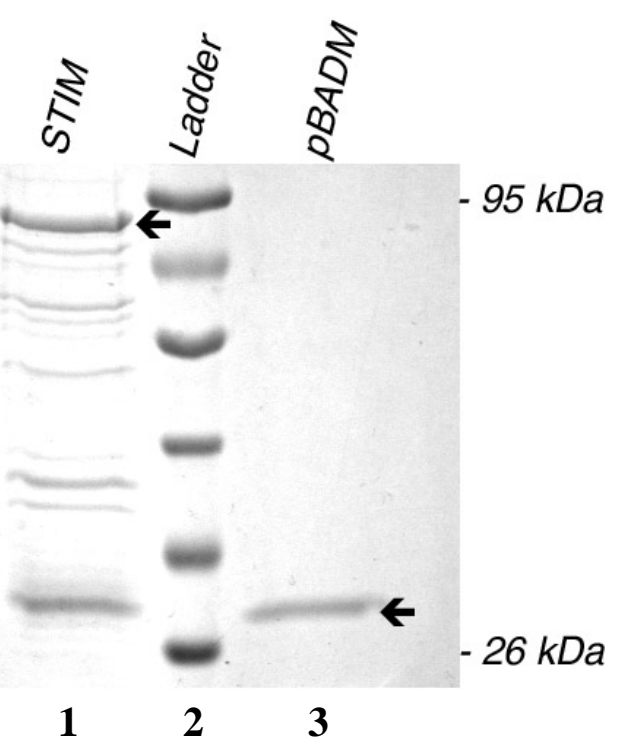

B)

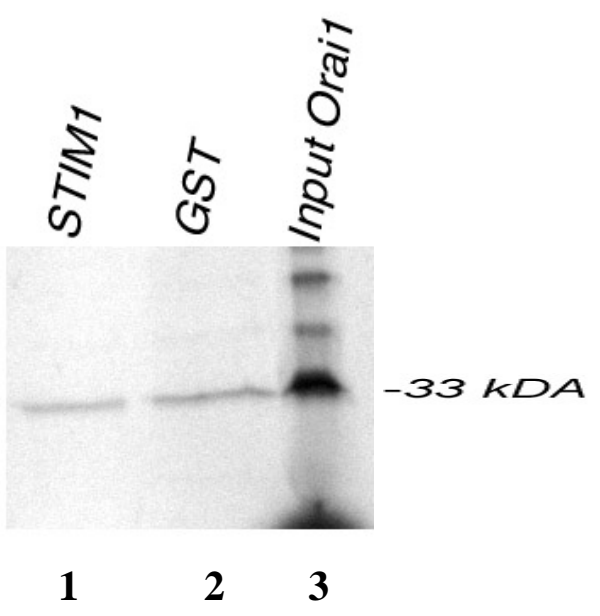

C)
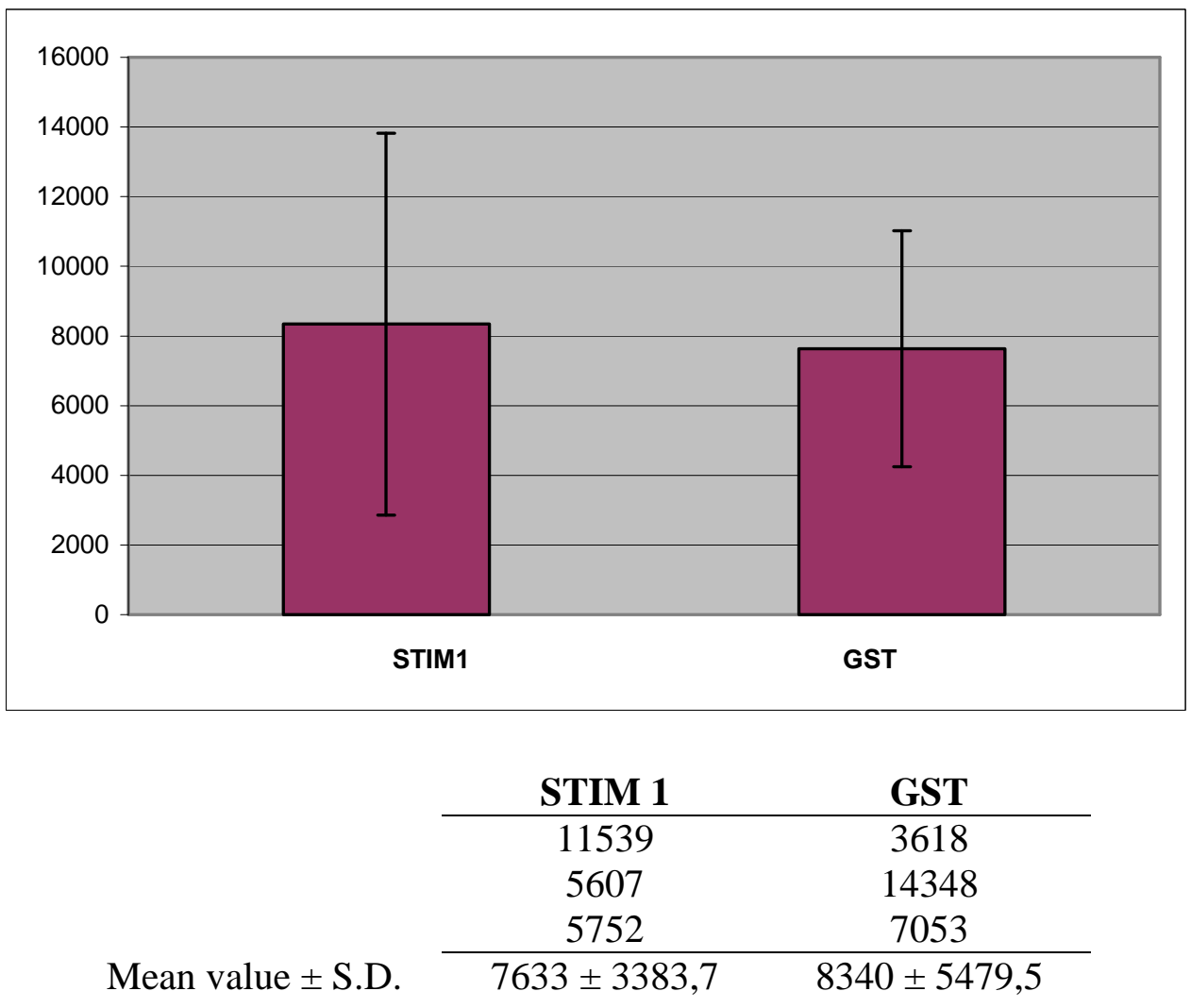

Figure 4: STIM1-C-terminus does not interact significantly with Orai1 full length in vitro

A) Protein expression in E. coli (see 2.1.3); STIM1-C-terminus + GST-Tag migrates at 90 $\mathrm{kDa}$ (arrow, lane 1); PageRuler ${ }^{\mathrm{TM}}$ Prestained-Protein-Ladder, Fermentas (lane 2); vector control (GST, arrow, lane 3)

B) GST-Pull-Down; Autoradiogramm: Retention of Orai1 on STIM1-C-terminus (lane1), GST without fused fragments (lane 2), Input of in vitro-translated ${ }^{35} \mathrm{~S}$-labeled Orai1 (lane 3)

C) Diagram and Table of values; mean of arbitrary units obtained by densitometrical analysis are shown for GST and GST-fused STIM1-C-terminus 


\subsection{TRPC3 does not precipitate with STIM1 or Orai1 in RBL wild type cells}

RBL wild type cells were lysed and proteins of the total cell lysate (500 $\mu \mathrm{g})$ were precipitated with anti-TRPC3 antibody, followed by immunoblotting.

Fig. 5 A) shows the detection of TRPC3 in controls and precipitates. The input of TRPC3 in lane 3 was very low and not sufficient for precipitating STIM1 or Orai1.

Detection was done with two different methods with different exposition times. So two lysates were used as positive control.

TG heart mouse lysate (lane 2) was used as positive control for densitometric analysis, T3-9 lysate (lane 1) for autoradiography and HUVEC lysate as negative control.

Fig. 5 B) displays detection of STIM1. HEK293 wild type lysate was used as positive control (lane 1) and also the input (lane 2) could be detected. There was no immunocomplex detectable, presumably due to the low input of TRPC3.

For Orai1 (Fig. 5 C) not even an input was detectable. This and the non-specific bands in the control (lane 3) were the reasons for further investigation of the principle quality of the used antibody (see below, Fig. 7).

\subsection{TRPC3 precipitates with STIM1 in RBL cells when overexpressed}

RBL cells were transfected with YFP-TRPC3 by lipofection. The fluorescence images of positive transfected cells are shown in Fig. 10.

In Fig. 6 A) YFP-tagged TRPC3 was detected at the expected molecular weight of $130 \mathrm{kDa}$ in lane 1 , representing the input, and in lane 2 , representing the precipitated immunocomplex.

Endogenous TRPC3 was not detectable, neither as input nor as complex.

RBL wild type lysate was used as positive control for detection by autoradiography and T3-9 for densitometric analysis.

Lane 2 of Fig. 6 B) shows the precipitated STIM1.

RBL wild type lysate was used as positive control for detection by autoradiography and HEK293 wild type for densitometric analysis. 
A)

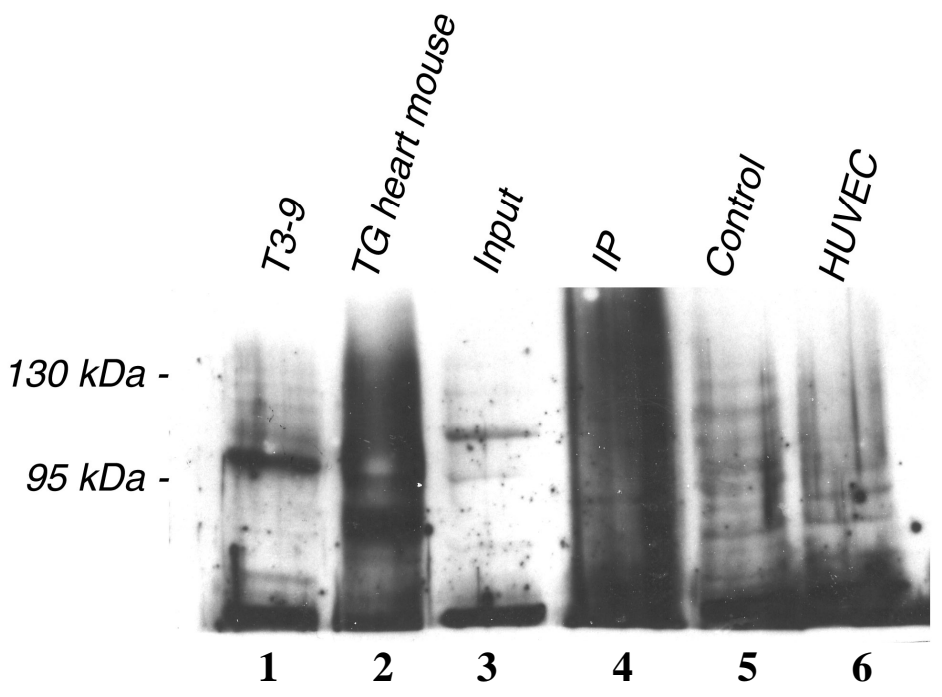

B)

C)

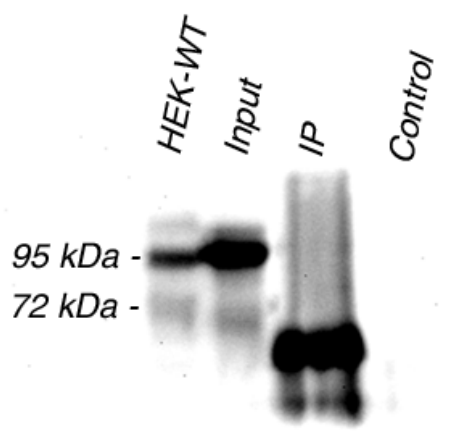

$\begin{array}{llll}1 & 2 & 3 & 4\end{array}$

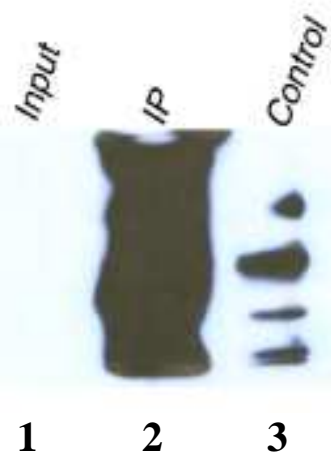

$1 \quad 2 \quad 3$

Figure 5: In RBL wild type cells TRPC3 does not precipitate with STIM1 or Orai1

Proteins $(500 \mu \mathrm{g})$ of total cell lysate of RBL wild type cells were precipitated with antiTRPC 3 antibody and immunoblotted against the indicated antibody. Input was $100 \mu \mathrm{g}$.

A) Blotted with anti-TRPC3 antibody: positive control for detection by autoradiograghy (lane 1), positive control for detection by densitometric analysis (lane 2), negative control (lane 6);

B) Blotted with anti-STIM1 antibody: HEK 293 wild type lysate was used as positive control;

C) Blotted with anti-Orai1 antibody; 
A)

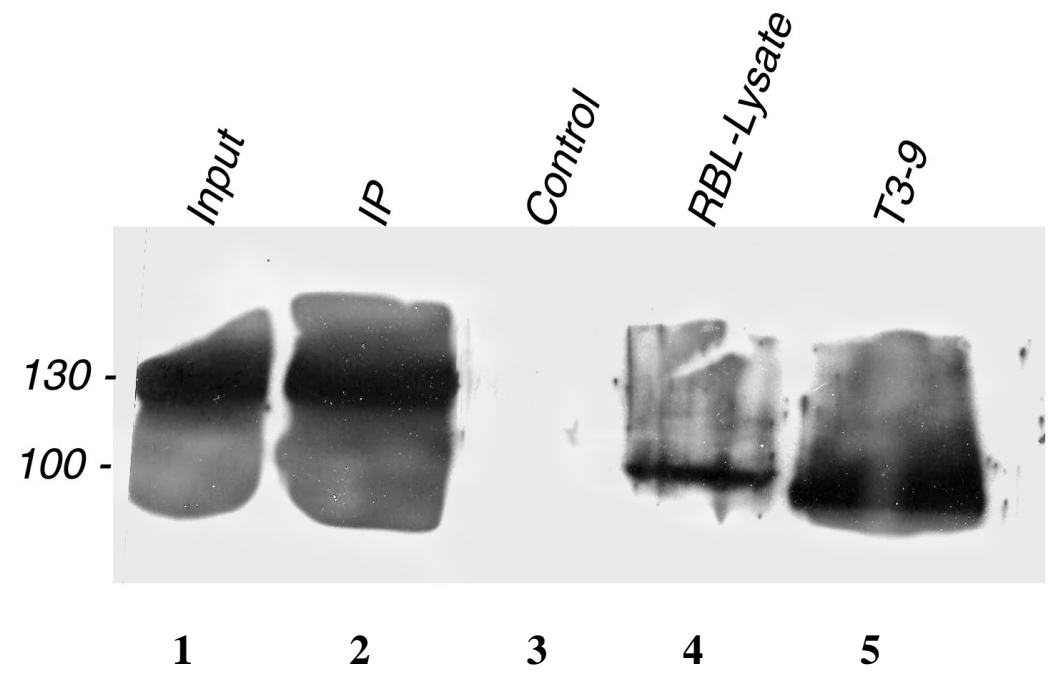

B)

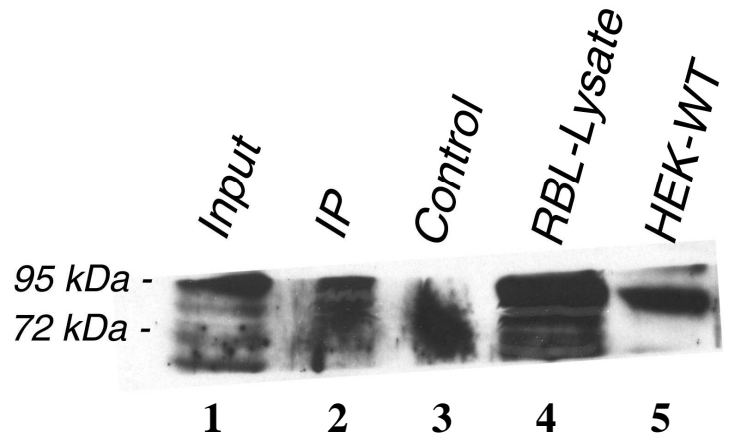

Figure 6: In RBL cells overexpressing YFP-TRPC3, TRPC3 precipitates with STIM1

Proteins $(500 \mu \mathrm{g})$ from RBL-expressing YFP-tagged TRPC3 cell lysate were precipitated with anti-TRPC3 antibody and blotted against the indicated antibody. Input was $100 \mu \mathrm{g}$.

A) Blotted against TRPC3 antibody: positive control for detection by autoradiography (lane 4) and by densitometric analysis (lane 5)

B) Blotted against STIM1 antibody: positive control for detection by densitometric analysis ( lane 4); positive control for detection by autoradiography (lane 5) 
A)

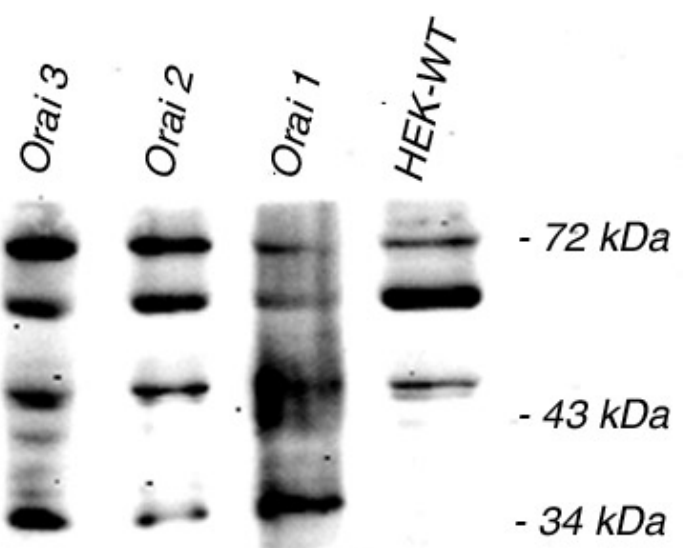

B)

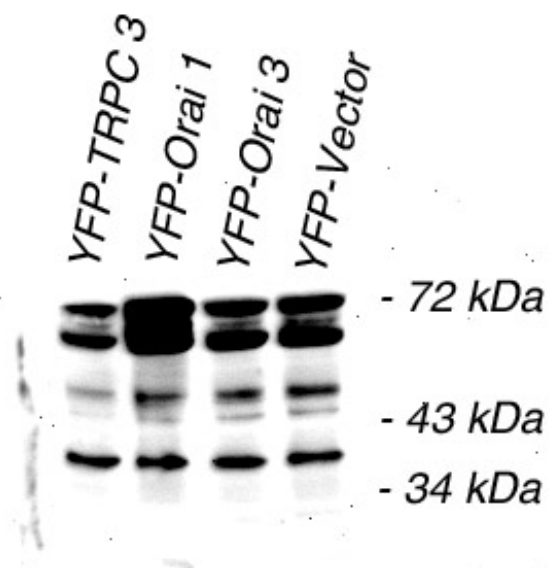

C)

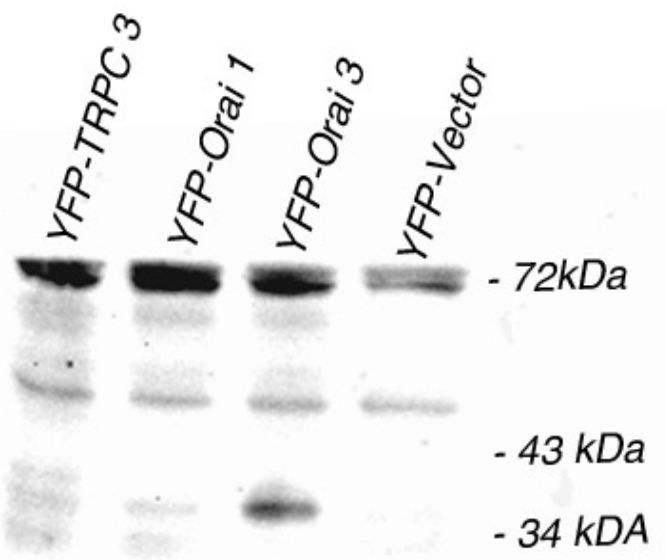

Figure 7: To test anti-Orai1 and anti-Orai3 antibody, different HEK293 cell lysates were blotted

A) HEK 293 cells were transfected with native Orai1, 2 and 3; total cell lysates $(100 \mu \mathrm{g})$ were blotted against Orai1

B) \& C) HEK 293 cells were transfected with YFP-TRPC3, YFP-Orai1 and YFP-Orai3; total cell lysates $(100 \mu \mathrm{g})$ were blotted against Orai1 (B) and Orai3 (C)

Table 15: possible molecular weights for Orai proteins

\begin{tabular}{l|c} 
& kDa \\
\hline Orai1 endogenous monomer & 33.1 \\
\hline Orai1 endogenous dimer & 66.2 \\
\hline Orai1 glycosylated monomer & 41 \\
\hline Orai1 glycosylated dimer & 82 \\
\hline Orai1 dimer native + glycosylated & 74 \\
\hline Data sheet Orai1 (PsiSci) & 51 \\
\hline Orai3 endogenous monomer & 32.5 \\
\hline Orai3 endogenous dimer & 65
\end{tabular}




\section{$\underline{3.5}$ Testing the quality of a commercially available Orai antibody}

HEK293 cells were transfected with tagged and untagged proteins by electroporation. The fluorescence images of positive transfected cells are shown in Fig. 9. Table 15 summarizes the possible molecular weights of Orai1 and Orai3 complexes. As shown in Fig. 7 it is not possible to distinguish between specific and unspecific bands and it is not clear if the antibodies distinguish between the different Orai proteins. The test should be repeated with purified proteins.

\subsection{B-catenin coprecipitates with TRPC4}

Fig. 8 A) shows the transfection control for T4-60 cells expressing B-catenin. The transfected ß-catenin was N-terminally tagged with YFP. The anti-ß-catenin antibody did not detect the tagged protein presumably because it also binds to the $\mathrm{N}$-terminus (left panel).

So in another blot, the tagged protein was detected with anti-GFP antibody (right panel).

Lane 1 and 4 in Fig. 8 B) represent the input of TRPC4, lane 2 and 5 show the immunocomplexes detected in both lysates.

For the control lanes the lysates were not treated with antibody. 
A)

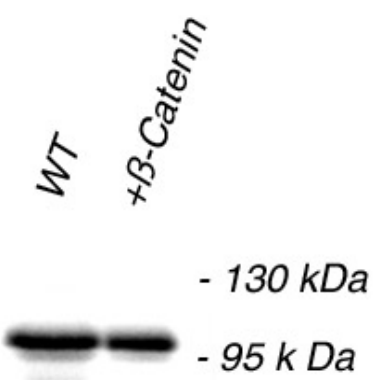

$\$ \int_{x}^{\stackrel{\delta}{\delta}}$

$130 \mathrm{kDa}$

$-95 k D a$

B)

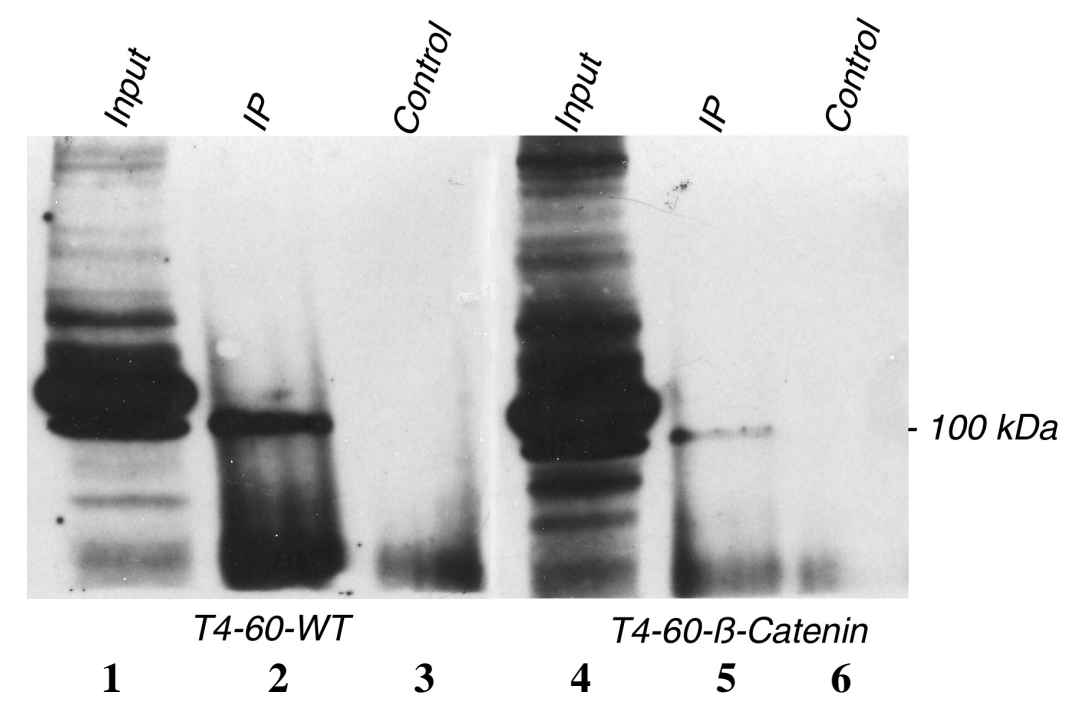

Figure 8: B-catenin precipitates with TRPC4

A) Total cell lysates from T4-60 wild type cells and T4-60, transfected with $\beta$-catenin, were blotted with anti-B-catenin antibody (left panel) and anti-GFP antibody (right panel);

B) Proteins $(500 \mu \mathrm{g})$ from total cell lysates of T4-60 wild type and T4-60, transfected with $\beta$-catenin, were precipitated with anti- $\beta$-catenin antibody and immunoblotted against TRPC4 antibody;

Lane 1 and 4: proteins from total cell lysates (Input $100 \mu \mathrm{g}$ )

Lane 2 and 5: cell lysates precipitated with anti- $\beta$-catenin antibody

Lane 3 and 6: control lysates, not treated with antibody 
A) YFP-Orai1

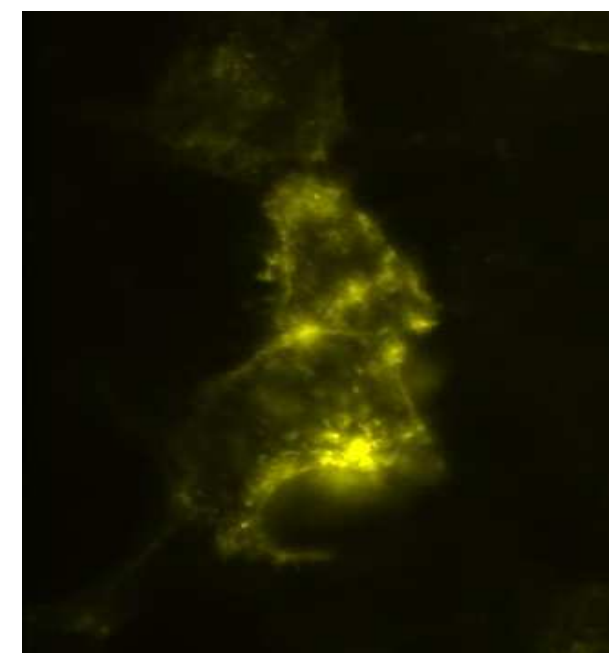

C) YFP-TRPC3

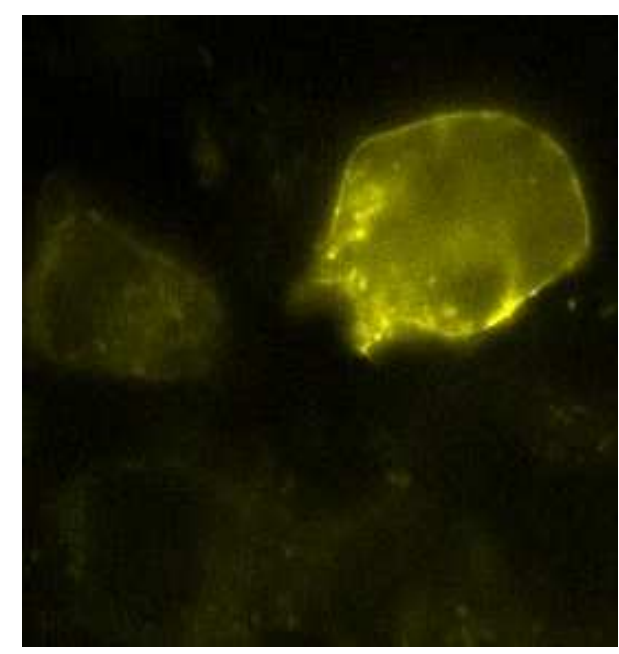

B)YFP- Orai3

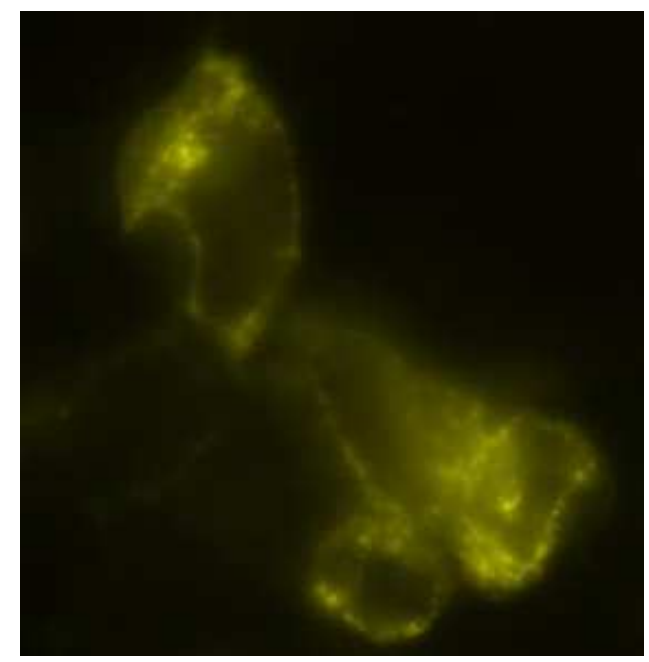

D) YFP-Vector

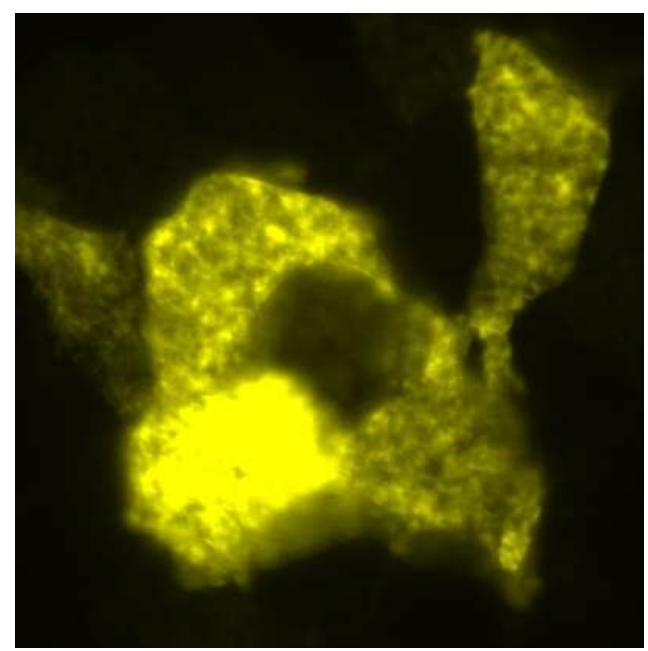

Figure 9: Fluorescence image of positive transfected HEK 293 cells

Representative parts of one coverslip are shown for each transfection. Proteins are located correctly in the plasma membrane. In visual light image, the cells looked morphologically normal (data not shown). Fluorescence imaging was done with a Zeiss Axiovert microscope. 


\section{YFP-TRPC3}
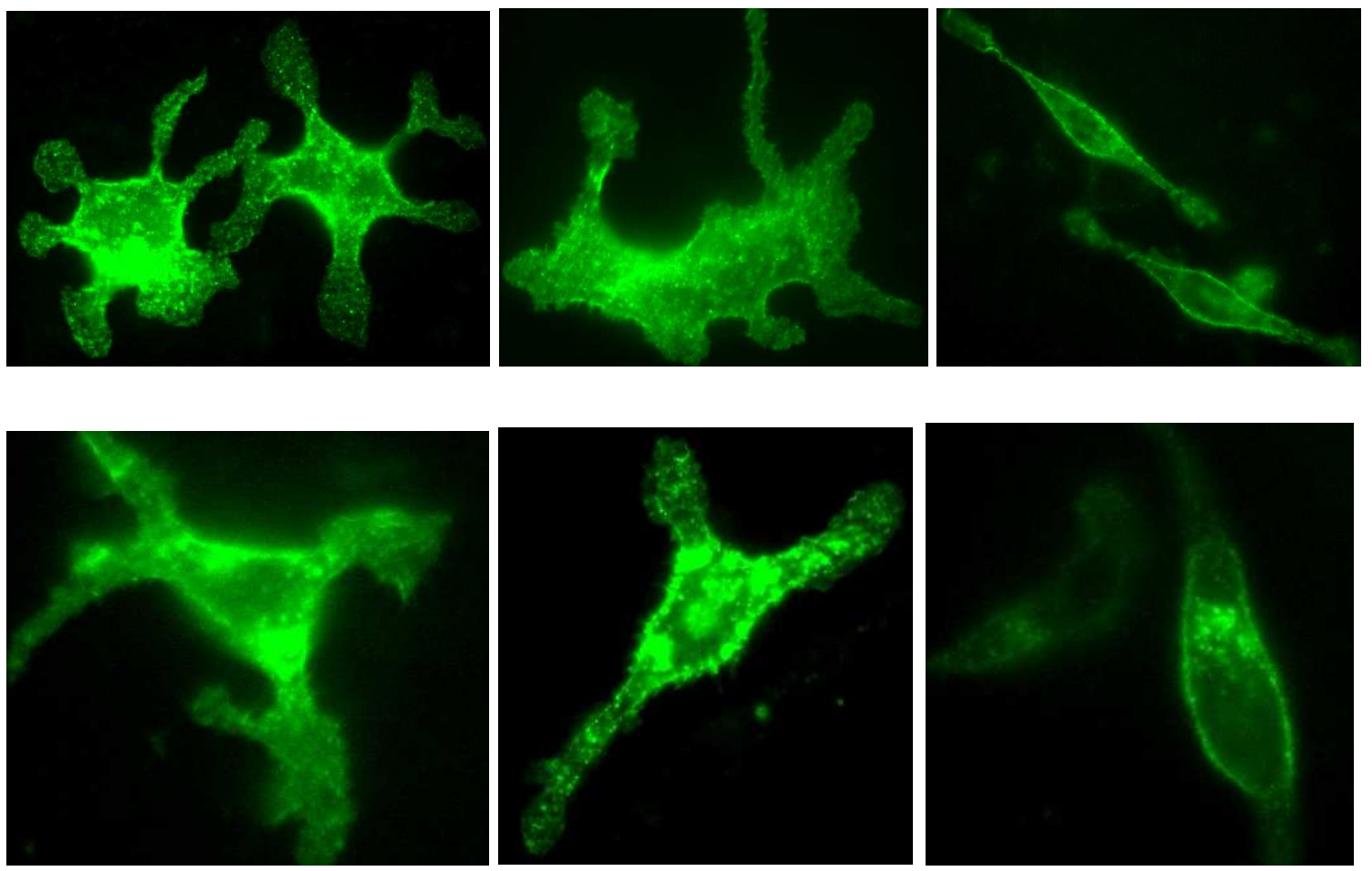

Figure 10: Fluorescence image of positive transfected RBL cells

Representative parts of one coverslip are shown. In visual light image, the cells looked morphologically normal (data not shown). Fluorescence imaging was done with a Zeiss Axiovert microscope. 


\section{Discussion}

\subsection{Interaction of TRPC3 and Orai1}

In 2006 the group of Birnbaumer reported that TRPC proteins are able to associate with Orai proteins to form a novel type of heteromeric SOCE channel. In in vitro GST-Pull Down experiments they showed that TRPC3 and TRPC6 form stable complexes with Orail. Moreover, they uncovered that Orai1 preferentially interacts with the C-termini of the TRPC proteins (Liao, et al. 2007).

Recently, Auberger (Diplomarbeit 2009) observed, that specific, small fragments of the TRPC3-C-terminus display interaction with Orai1 in vitro using a GST-pull down/ in vitro transcription-translation approach.

In this study, the results of Auberger, which suggested a binding site on the TRPC3-Cterminus between amino acids 670-797 were confirmed (Fig. 3).

This fragment contains the TRP-Box, a highly conserved sequence within the TRPC proteins, and the CIRB region, the interaction site for calmodulin and the $\mathrm{IP}_{3}$ receptor (Zhang, et al. 2001). We suggest a model in which TRPC3 forms heteromeric channels with Orai1 after dissociation of the inhibitory calmodulin from the $\mathrm{C}$-terminus and propose a role for Orail in membrane targeting of TRPC3. Zhu et al. reported that TRPC3 activity is inhibited by $\mathrm{Ca}^{2+}$ and calmodulin and proposed that IP3 receptors activate TRPC channels by displacing the inhibitory calmodulin of the CIRB region (Zhu and Tang 2004). However, it was found out that TRPC3 targets to the plasma membrane and forms functional channels in DT40 cells lacking all three $\mathrm{IP}_{3}$ receptors (Wedel, et al. 2003). It was suggested that CIRB governs the membrane localisation and targeting independent of $\mathrm{IP}_{3} \mathrm{R}$ - and calmodulin-interactions. Thus, the interaction with Orai may alternatively compete with calmodulin binding at the TRPC3 Cterminus, thereby enabling membrane recruitment and store-dependent activation. This speculation is so far only based on the here demonstrated binding of Orail to the CIRB region, which has been clearly identified as a structure essential for correct channel targeting. Consistently, deletions in this region were found to impair TRPC3 function and prevent its targeting to the plasma membrane (Wedel, et al. 2003). 
Unfortunately, using native mast cells (RBL), binding of endogenous Orai1 to TRPC3 could not be detected by immunoprecipitation (Fig. 5C). So we were prompted to evaluate the principle quality of the used antibody. As shown in Fig. 7 it is not clear if the antibody is able to distinguish between the different Orai proteins because the detection of Orai1 in a lysate of Orai1-transfected cells does not show significant differences to the detection of Orai1 in a lysate of Orai3-transfected cells. As demonstrated in Table 15, the molecular weight of endogenous Orail can not be defined definitely. Because this is obviously a common problem, Orai1 is only detected as tagged protein in other studies (Gwack, et al. 2007).

\section{$\underline{4.2}$ Interaction of Orai1 and STIM1}

There are studies which report the colocalisation and coimmunoprecipitation of Drosophila Orai1 and STIM1 and human Orai1 and STIM1 (Yeromin, et al. 2006, Vig, et al. 2006) but also studies from a different laboratory which failed to detect any association in coimmunoprecipitation and glycerol gradient centrifugation experiments (Feske, et al. 2006, Gwack, et al. 2007).

The only report of the interaction of STIM1-C-terminus and Orai1 in cell free conditions with in vitro Pull Down experiments was published by Muik et al. They could also show a close interaction between tagged Orail and tagged STIM1, when expressed in HEK293, using FRET microscopy (Muik, et al. 2008).

Auberger (Diplomarbeit 2009) could not detect any significant interaction by in vitro HIS-tagPull Down assays of STIM1-C-terminus and Orai1.

In the present study the interaction was not significantly detectable by GST-Pull Down assays (Fig. 4). One explanation for the discrepancy between experiments in intact cells and in vitro pull-down assays may be that, bound to Sepharose beads, STIM1-C-terminus may not be able to form multimers, which are required for the interaction with Orai1 (Muik, et al. 2008). Wu et al. reported the redistribution of STIM1 into puncta upon store-depletion. Hence, this clustering is considered as an essential step SOCE activation, because puncta formation precedes CRAC channel activation by 6-10 s (Wu, et al. 2006). 
It is still not clear if STIM conveys information to Orai1 via direct protein-protein interaction or through intermediary proteins.

The idea, a soluble diffusible messenger, called calcium influx factor CIF, could be involved came up by Takemura et al. and was further investigated by Bolotina and colleagues (Takemura, et al. 1989, Bolotina and Csutora 2005). They report that STIM1 is a trigger for CIF production (Csutora, et al. 2008). CIF stimulates calcium influx (Randriamampita and Tsien 1993).

\subsection{Interaction of TRPC3 and STIM1}

There is evidence that TRPC channels exist in a complex with Orai1 and STIM1 (Liao, et al. 2007, Liao, et al. 2008, Ong, et al. 2007).

Huang et al. reported that STIM1 binds TRPC1, TRPC4 and TRPC5 and regulates them directly but STIM1 does not bind TRPC3 and TRPC6 and regulates them indirectly (Huang, et al. 2006).

Zeng et al. showed that STIM1 gates TRPC1 by intermolecular electrostatic interaction between two negatively charged aspartates in TRPC1 and a polybasic domain in STIM1. This could also be shown for TRPC3. Thus, they suggested that gating by electrostatic interaction is a general mechanism for all TRPCs, equal if directly or indirectly regulated (Zeng, et al. 2008).

Though the results of other groups indicate a role for STIM1 in TRPC regulation DeHaven et al. concluded after imaging and electrophysiological experiments, that TRPC1, TRPC3, TRPC5, TRPC6 and TRPC7 function independently of STIM1. They suggest TRPC channels to be activated by phospholipase $\mathrm{C}$ dependent mechanisms without STIM1-interaction (DeHaven, et al. 2009).

However, in our experiments we could detect an immunocomplex of TRPC3 and STIM1 in RBL cell lysate when TRPC3 was overexpressed (Fig.6).

This was not possible in RBL wild type lysate. As shown in Fig. 5A the expression level of endogenous TRPC3 is very low and may not be sufficient to precipitate with STIM1 (Fig. $5 B)$. 


\subsection{Interaction of TRPC4 and ß-catenin}

The proposed role of TRPC4 as a channel that controls the stability of cell-cell junctions prompted us to test for an interaction of TRPC4 with junctional proteins. Indeed we were able to show that TRPC4 coprecipitates with $\beta$-catenin (Fig. 8) in T4-60 cells, a HEK293 cell line stably expressing TRPC4.

Graziani recently observed that TRPC4 precipitates with $\beta$-catenin in HMEC (Human Microvascular Endothelial Cells) also and, furthermore, it precipitates with VE-cadherin. They analyzed the cellular location and function of TRPC4 in absence and presence of cellcell adhesion contacts and found out that the formation of cell-cell contacts promotes recruitment of TRPC4 into plasma membrane complexes. Their results indicate $\beta$-catenin as a key regulator of TRPC4-mediated $\mathrm{Ca}^{2+}$ signalling in endothelial cells. (Graziani et al. 2009, unpublished data). As a molecular mechanism for the association of TRPC4 with $\beta$-catenin it is tempting to speciulate about an involvement of PDZ domain containing proteins that may serve as linker between these proteins which both contain PDZ interacting sequences

NHERF proteins contain two PDZ domains. Therefore they can associate with two different molecules. There is evidence that TRPC4 binds to NHERF at its first PDZ domain (Mery, et al. 2002) and that NHERF binds strongly to $\beta$-catenin with its second PDZ domain (Theisen, et al. 2007).

Thus, the interaction of TRPC4 and $\beta$-catenin could be indirect and mediated by NHERF via forming a ternary complex.

Interestingly, endogenous $\beta$-catenin precipitates preferentially with TRPC4 as shown for untransfected T4-60 cells in Fig. 8 B, while this interaction was reduced in T4-60 cells, transfected with YFP- $\beta$-catenin. The weaker interaction may be explained by a dominant negative effect of the tagged protein. The tagged $\beta$-catenin may bind to NHERF and it is no longer available for forming ternary complexes with endogenous $\beta$-catenin and TRPC4.

In summary the results of this work confirmed and demonstrated novel interaction partners for TRPC3 and TRPC4, involving STIM1, Orai 1 and $\beta$-catenin. STIM1 functions as a potential activator for TRPC3 and Orai1 as a putative subunit of a heteromeric ion channel formed by a TRPC3/Orai1-complex. That TRPC4 interacts with the junctional protein $\beta$-catenin supports the suggestion for TRPC4 to play an essential role in controlling the stability of cell-cell junctions. 


\section{Abstract}

The present study investigated protein-protein interactions of TRPC channel proteins.

TRPC channels represent one of the seven subfamilies or the TRP (transient receptor potential) family of ion channels termed the "canonical" subfamily. TRPC channels are widely expressed functionally in different tissues and appear to be involved in many physiological and pathophysiological processes. They are typically activated by stimulating G-protein coupled receptors linked to PLC $\beta$ and via tyrosine kinase receptors linked to PLC $\gamma$. PLC hydrolyses $\mathrm{PIP}_{2}$ into two messengers, DAG and $\mathrm{InsP}_{3}$, which binds to the $\mathrm{InsP}_{3}$ receptor and causes intracellular $\mathrm{Ca}^{2+}$ release from the endoplasmic reticulum.

Other activation mechanisms suggested for TRPC channels are conformational coupling between $\mathrm{InsP}_{3}$ receptor and TRPC or activation by direct interaction with Diacylglycerol or Lysophosphatidylcholine. TRPC channels were postulated as pore forming molecules, responsible for receptor and store depletion activated calcium entry.

Changes in intracellular calcium regulate many important physiological functions in cells.

These can be short term responses like regulation of exocytosis and also long-term responses like regulating gene transcription. If the regulation of these essential functions is impaired, pathophysiological processes like severe combined immunodeficiency, acute pancreatitis or Alzheimer's disease can occur.

We investigated the potential regulatory interaction of TRPC3 with STIM1 and Orai1 and the interaction of TRPC4 with $\beta$-catenin.

STIM1 is a single transmembrane protein with its luminal N-terminus, containing a single EFhand domain acting as $\mathrm{Ca}^{2+}$ binding motif and as luminal $\mathrm{Ca}^{2+}$ sensor.

The Orai protein could be identified to mediate the CRAC current.

$\beta$-catenin plays an important role in adherens junctions, it creates the link between cadherins and the actin cytoskeleton through its interaction with $\alpha$-catenin. It also has an essential role in Wnt-signaling.

To demonstrate the interactions under selected conditions we used an in vitro GST-pull down/ in vitro transcription-translation approach and coimmunoprecipitation experiments to observe the direct interactions.

The results obtained from these experiments led us to conclude that TRPC3 interacts with STIM1 and Orai1 and that Orai1 may form heteromeric channels with TRPC3 which are activated by STIM1. 
The detectable interaction of TRPC4 with $\beta$-catenin seems to be not direct but mediated by a scaffold protein named NHERF.

In summary the results of this work confirmed and demonstrated novel interaction partners for TRPC3 and TRPC4, involving STIM1, Orai 1 and $\beta$-catenin. STIM1 functions as a potential activator for TRPC3 and Orai1 as a putative subunit of a heteromeric ion channel formed by a TRPC3/Orai1-complex. The TRPC4 interaction with the junctional protein $\beta$-catenin, which is possibly mediated via the scaffold protein NHERF, supports the suggestion for TRPC4 to play an essential role in controlling the stability of cell-cell junctions. 


\section{References}

1. Montell, C., and Rubin, G. M. (1989) Molecular characterization of the Drosophila trp locus: a putative integral membrane protein required for phototransduction. Neuron $\mathbf{2}$, 1313-1323

2. Hardie, R. C., and Raghu, P. (2001) Visual transduction in Drosophila. Nature 413, 186-193

3. Hardie, R. C., and Minke, B. (1992) The trp gene is essential for a light-activated $\mathrm{Ca} 2+$ channel in Drosophila photoreceptors. Neuron 8, 643-651

4. Venkatachalam, K., and Montell, C. (2007) TRP channels. Annu Rev Biochem 76, $387-417$

5. Zhu, X., Chu, P. B., Peyton, M., and Birnbaumer, L. (1995) Molecular cloning of a widely expressed human homologue for the Drosophila trp gene. FEBS Lett 373, 193 198

6. Wes, P. D., Chevesich, J., Jeromin, A., Rosenberg, C., Stetten, G., and Montell, C. (1995) TRPC1, a human homolog of a Drosophila store-operated channel. Proc Natl Acad Sci U S A 92, 9652-9656

7. Abramowitz, J., and Birnbaumer, L. (2009) Physiology and pathophysiology of canonical transient receptor potential channels. FASEB J 23, 297-328

8. Clapham, D. E. (2003) TRP channels as cellular sensors. Nature 426, 517-524

9. Birnbaumer, L. (2009) The TRPC class of ion channels: a critical review of their roles in slow, sustained increases in intracellular $\mathrm{Ca}(2+)$ concentrations. Annu Rev Pharmacol Toxicol 49, 395-426

10. Parekh, A. B., and Putney, J. W., Jr. (2005) Store-operated calcium channels. Physiol $\operatorname{Rev} \mathbf{8 5}, 757-810$

11. Hoth, M., and Penner, R. (1992) Depletion of intracellular calcium stores activates a calcium current in mast cells. Nature 355, 353-356

12. Zweifach, A., and Lewis, R. S. (1993) Mitogen-regulated Ca2+ current of T lymphocytes is activated by depletion of intracellular Ca2+ stores. Proc Natl Acad Sci U S A 90, 6295-6299

13. Feske, S., Gwack, Y., Prakriya, M., Srikanth, S., Puppel, S. H., Tanasa, B., Hogan, P. G., Lewis, R. S., Daly, M., and Rao, A. (2006) A mutation in Orail causes immune deficiency by abrogating CRAC channel function. Nature 441, 179-185

14. Vig, M., Peinelt, C., Beck, A., Koomoa, D. L., Rabah, D., Koblan-Huberson, M., Kraft, S., Turner, H., Fleig, A., Penner, R., and Kinet, J. P. (2006) CRACM1 is a plasma membrane protein essential for store-operated Ca2+ entry. Science 312, 12201223 
15. Zhang, S. L., Yeromin, A. V., Zhang, X. H., Yu, Y., Safrina, O., Penna, A., Roos, J., Stauderman, K. A., and Cahalan, M. D. (2006) Genome-wide RNAi screen of $\mathrm{Ca}(2+)$ influx identifies genes that regulate $\mathrm{Ca}(2+)$ release-activated $\mathrm{Ca}(2+)$ channel activity. Proc Natl Acad Sci U S A 103, 9357-9362

16. Roos, J., DiGregorio, P. J., Yeromin, A. V., Ohlsen, K., Lioudyno, M., Zhang, S., Safrina, O., Kozak, J. A., Wagner, S. L., Cahalan, M. D., Velicelebi, G., and Stauderman, K. A. (2005) STIM1, an essential and conserved component of storeoperated Ca2+ channel function. J Cell Biol 169, 435-445

17. Spassova, M. A., Soboloff, J., He, L. P., Xu, W., Dziadek, M. A., and Gill, D. L. (2006) STIM1 has a plasma membrane role in the activation of store-operated $\mathrm{Ca}(2+)$ channels. Proc Natl Acad Sci U S A 103, 4040-4045

18. Liou, J., Kim, M. L., Heo, W. D., Jones, J. T., Myers, J. W., Ferrell, J. E., Jr., and Meyer, T. (2005) STIM is a Ca2+ sensor essential for Ca2+-store-depletion-triggered Ca2+ influx. Curr Biol 15, 1235-1241

19. Zheng, L., Stathopulos, P. B., Li, G. Y., and Ikura, M. (2008) Biophysical characterization of the EF-hand and SAM domain containing $\mathrm{Ca} 2+$ sensory region of STIM1 and STIM2. Biochem Biophys Res Commun 369, 240-246

20. Soboloff, J., Spassova, M. A., Hewavitharana, T., He, L. P., Xu, W., Johnstone, L. S., Dziadek, M. A., and Gill, D. L. (2006) STIM2 is an inhibitor of STIM1-mediated store-operated Ca2+ Entry. Curr Biol 16, 1465-1470

21. Luik, R. M., Wu, M. M., Buchanan, J., and Lewis, R. S. (2006) The elementary unit of store-operated $\mathrm{Ca} 2+$ entry: local activation of CRAC channels by STIM1 at ERplasma membrane junctions. J Cell Biol 174, 815-825

22. Muik, M., Fahrner, M., Derler, I., Schindl, R., Bergsmann, J., Frischauf, I., Groschner, K., and Romanin, C. (2009) A Cytosolic Homomerization and a Modulatory Domain within STIM1 C Terminus Determine Coupling to ORAI1 Channels. J Biol Chem 284, $8421-8426$

23. Zeng, W., Yuan, J. P., Kim, M. S., Choi, Y. J., Huang, G. N., Worley, P. F., and Muallem, S. (2008) STIM1 gates TRPC channels, but not Orai1, by electrostatic interaction. Mol Cell 32, 439-448

24. Cahalan, M. D., Zhang, S. L., Yeromin, A. V., Ohlsen, K., Roos, J., and Stauderman, K. A. (2007) Molecular basis of the CRAC channel. Cell Calcium 42, 133-144

25. Gwack, Y., Srikanth, S., Feske, S., Cruz-Guilloty, F., Oh-hora, M., Neems, D. S., Hogan, P. G., and Rao, A. (2007) Biochemical and functional characterization of Orai proteins. J Biol Chem 282, 16232-16243

26. Lis, A., Peinelt, C., Beck, A., Parvez, S., Monteilh-Zoller, M., Fleig, A., and Penner, R. (2007) CRACM1, CRACM2, and CRACM3 are store-operated Ca2+ channels with distinct functional properties. Curr Biol 17, 794-800 
27. Penna, A., Demuro, A., Yeromin, A. V., Zhang, S. L., Safrina, O., Parker, I., and Cahalan, M. D. (2008) The CRAC channel consists of a tetramer formed by Stiminduced dimerization of Orai dimers. Nature 456, 116-120

28. Brembeck, F. H., Rosario, M., and Birchmeier, W. (2006) Balancing cell adhesion and Wnt signaling, the key role of beta-catenin. Curr Opin Genet Dev 16, 51-59

29. Bienz, M. (2005) beta-Catenin: a pivot between cell adhesion and Wnt signalling. Curr Biol 15, R64-67

30. Theisen, C. S., Wahl, J. K., 3rd, Johnson, K. R., and Wheelock, M. J. (2007) NHERF links the N-cadherin/catenin complex to the platelet-derived growth factor receptor to modulate the actin cytoskeleton and regulate cell motility. Mol Biol Cell 18, 12201232

31. Tang, Y., Tang, J., Chen, Z., Trost, C., Flockerzi, V., Li, M., Ramesh, V., and Zhu, M. X. (2000) Association of mammalian trp4 and phospholipase C isozymes with a PDZ domain-containing protein, NHERF. J Biol Chem 275, 37559-37564

32. Birnbaumer, L., Zhu, X., Jiang, M., Boulay, G., Peyton, M., Vannier, B., Brown, D., Platano, D., Sadeghi, H., Stefani, E., and Birnbaumer, M. (1996) On the molecular basis and regulation of cellular capacitative calcium entry: roles for Trp proteins. Proc Natl Acad Sci U S A 93, 15195-15202

33. Zagranichnaya, T. K., Wu, X., and Villereal, M. L. (2005) Endogenous TRPC1, TRPC3, and TRPC7 proteins combine to form native store-operated channels in HEK293 cells. J Biol Chem 280, 29559-29569

34. Feske, S. (2007) Calcium signalling in lymphocyte activation and disease. Nat Rev Immunol 7, 690-702

35. Hogan, P. G., and Rao, A. (2007) Dissecting ICRAC, a store-operated calcium current. Trends Biochem Sci 32, 235-245

36. Vig, M., and Kinet, J. P. (2007) The long and arduous road to CRAC. Cell Calcium 42, $157-162$

37. Liao, Y., Erxleben, C., Yildirim, E., Abramowitz, J., Armstrong, D. L., and Birnbaumer, L. (2007) Orai proteins interact with TRPC channels and confer responsiveness to store depletion. Proc Natl Acad Sci U S A 104, 4682-4687

38. Liao, Y., Plummer, N. W., George, M. D., Abramowitz, J., Zhu, M. X., and Birnbaumer, L. (2009) A role for Orai in TRPC-mediated Ca2+ entry suggests that a TRPC:Orai complex may mediate store and receptor operated Ca2+ entry. Proc Natl Acad Sci U S A 106, 3202-3206

39. Alicia, S., Angelica, Z., Carlos, S., Alfonso, S., and Vaca, L. (2008) STIM1 converts TRPC1 from a receptor-operated to a store-operated channel: moving TRPC1 in and out of lipid rafts. Cell Calcium 44, 479-491 
40. Huang, G. N., Zeng, W., Kim, J. Y., Yuan, J. P., Han, L., Muallem, S., and Worley, P. F. (2006) STIM1 carboxyl-terminus activates native SOC, I(crac) and TRPC1 channels. Nat Cell Biol 8, 1003-1010

41. Yuan, J. P., Zeng, W., Huang, G. N., Worley, P. F., and Muallem, S. (2007) STIM1 heteromultimerizes TRPC channels to determine their function as store-operated channels. Nat Cell Biol 9, 636-645

42. Freichel, M., Suh, S. H., Pfeifer, A., Schweig, U., Trost, C., Weissgerber, P., Biel, M., Philipp, S., Freise, D., Droogmans, G., Hofmann, F., Flockerzi, V., and Nilius, B. (2001) Lack of an endothelial store-operated Ca2+ current impairs agonist-dependent vasorelaxation in TRP4-/- mice. Nat Cell Biol 3, 121-127

43. Tiruppathi, C., Freichel, M., Vogel, S. M., Paria, B. C., Mehta, D., Flockerzi, V., and Malik, A. B. (2002) Impairment of store-operated Ca2+ entry in TRPC4(-/-) mice interferes with increase in lung microvascular permeability. Circ Res 91, 70-76

44. Mery, L., Strauss, B., Dufour, J. F., Krause, K. H., and Hoth, M. (2002) The PDZinteracting domain of TRPC4 controls its localization and surface expression in HEK293 cells. J Cell Sci 115, 3497-3508

45. Bradford, H. F., and Richards, C. D. (1976) Specific release of endogenous glutamate from piriform cortex stimulated in vitro. Brain Res 105, 168-172

46. Zhang, Z., Tang, J., Tikunova, S., Johnson, J. D., Chen, Z., Qin, N., Dietrich, A., Stefani, E., Birnbaumer, L., and Zhu, M. X. (2001) Activation of Trp3 by inositol 1,4,5-trisphosphate receptors through displacement of inhibitory calmodulin from a common binding domain. Proc Natl Acad Sci U S A 98, 3168-3173

47. Zhu, M. X., and Tang, J. (2004) TRPC channel interactions with calmodulin and IP3 receptors. Novartis Found Symp 258, 44-58; discussion 58-62, 98-102, 263-106

48. Wedel, B. J., Vazquez, G., McKay, R. R., St, J. B. G., and Putney, J. W., Jr. (2003) A calmodulin/inositol 1,4,5-trisphosphate (IP3) receptor-binding region targets TRPC3 to the plasma membrane in a calmodulin/IP3 receptor-independent process. $J$ Biol Chem 278, 25758-25765

49. Yeromin, A. V., Zhang, S. L., Jiang, W., Yu, Y., Safrina, O., and Cahalan, M. D. (2006) Molecular identification of the CRAC channel by altered ion selectivity in a mutant of Orai. Nature 443, 226-229

50. Vig, M., Beck, A., Billingsley, J. M., Lis, A., Parvez, S., Peinelt, C., Koomoa, D. L., Soboloff, J., Gill, D. L., Fleig, A., Kinet, J. P., and Penner, R. (2006) CRACM1 multimers form the ion-selective pore of the CRAC channel. Curr Biol 16, 2073-2079

51. Muik, M., Frischauf, I., Derler, I., Fahrner, M., Bergsmann, J., Eder, P., Schindl, R., Hesch, C., Polzinger, B., Fritsch, R., Kahr, H., Madl, J., Gruber, H., Groschner, K., and Romanin, C. (2008) Dynamic coupling of the putative coiled-coil domain of ORAI1 with STIM1 mediates ORAI1 channel activation. J Biol Chem 283, 8014-8022 
52. Wu, M. M., Buchanan, J., Luik, R. M., and Lewis, R. S. (2006) Ca2+ store depletion causes STIM1 to accumulate in ER regions closely associated with the plasma membrane. J Cell Biol 174, 803-813

53. Takemura, H., Hughes, A. R., Thastrup, O., and Putney, J. W., Jr. (1989) Activation of calcium entry by the tumor promoter thapsigargin in parotid acinar cells. Evidence that an intracellular calcium pool and not an inositol phosphate regulates calcium fluxes at the plasma membrane. J Biol Chem 264, 12266-12271

54. Bolotina, V. M., and Csutora, P. (2005) CIF and other mysteries of the store-operated Ca2+-entry pathway. Trends Biochem Sci 30, 378-387

55. Csutora, P., Peter, K., Kilic, H., Park, K. M., Zarayskiy, V., Gwozdz, T., and Bolotina, V. M. (2008) Novel role for STIM1 as a trigger for calcium influx factor production. $J$ Biol Chem 283, 14524-14531

56. Randriamampita, C., and Tsien, R. Y. (1993) Emptying of intracellular Ca2+ stores releases a novel small messenger that stimulates Ca2+ influx. Nature 364, 809-814

57. Liao, Y., Erxleben, C., Abramowitz, J., Flockerzi, V., Zhu, M. X., Armstrong, D. L., and Birnbaumer, L. (2008) Functional interactions among Orai1, TRPCs, and STIM1 suggest a STIM-regulated heteromeric Orai/TRPC model for SOCE/Icrac channels. Proc Natl Acad Sci U S A 105, 2895-2900

58. Ong, H. L., Cheng, K. T., Liu, X., Bandyopadhyay, B. C., Paria, B. C., Soboloff, J., Pani, B., Gwack, Y., Srikanth, S., Singh, B. B., Gill, D. L., and Ambudkar, I. S. (2007) Dynamic assembly of TRPC1-STIM1-Orai1 ternary complex is involved in storeoperated calcium influx. Evidence for similarities in store-operated and calcium release-activated calcium channel components. J Biol Chem 282, 9105-9116

59. DeHaven, W. I., Jones, B. F., Petranka, J. G., Smyth, J. T., Tomita, T., Bird, G. S., and Putney, J. W., Jr. (2009) TRPC channels function independently of STIM1 and Orai1. J Physiol 587, 2275-2298 


\section{Abbreviations}

CIF

CIRB region

CRAC

C-terminus

DAG

DMEM

EBP50

FBS

FRET

GFP

GST

HEK

HMEC

HUVEC

Ins $\mathrm{P}_{3} / \mathrm{IP}_{3}$

IPTG

$\mathrm{kDa}$

LB

NHERF

PAGE

PBS

PIP2

PLC

RBL
Calcium influx factor

Calmodulin inositol-triphosphat receptor binding region

Calcium release activated current

Carboxy-terminus

1,2-Diacylglycerol

Dulbecco`s Modified Eagle`s Medium

ezrin/moesin/radixin-binding phosphoprotein 50

Foetal bovine serum

Fluorescence Resonance Energy Transfer

Green Fluorescence Protein

Glutathione-S-Transferase

Human Embryonic Kidney

Human Microvascular Endothelial Cells

Human Umbilical Vein Endothelial Cells

inositol-1,4,5-trisphosphate

isopropyl- $\beta$-D-thiogalactopyranoside

kilo Dalton

Luria Bertani

$\mathrm{Na}+\mathrm{H}+$ exchanger regulatory factor

polyacrylamide gel electrophoresis

phosphate buffered saline

phosphatidylinositol-4,5-bisphosphate

phospholipase $\mathrm{C}$

rat basophilic leukaemia 
$\mathrm{rpm}$

rounds per minute

SAM

sterile alpha motif

SDS

sodium dodecylsulfate

SOCE

store-operated calcium entry

STIM

Stromal Interacting Molecule

TRP

transient receptor potential

T3-9

HEK293 cell line stably expressing TRPC3

T4-60

HEK293 cell line stably expressing TRPC4

VE-cadherin

vascular endothelial-cadherin

YFP

Yellow Fluorescence Protein 